\title{
Functional Roles of Complexin 3 and Complexin 4 at Mouse Photoreceptor Ribbon Synapses
}

\author{
[DNorbert Babai, ${ }^{1}$ Anna Sendelbeck, ${ }^{1}$ Hanna Regus-Leidig, ${ }^{1}{ }^{\oplus}$ Michaela Fuchs, ${ }^{1}$ Jasmin Mertins, ${ }^{1}$ Kerstin Reim, ${ }^{2}$ \\ № Nils Brose, ${ }^{2}$ Andreas Feigenspan, ${ }^{1}$ and ${ }^{\circ}$ Johann Helmut Brandstätter ${ }^{1}$ \\ ${ }^{1}$ Department of Biology, Animal Physiology, Friedrich Alexander University Erlangen-Nürnberg, 91058 Erlangen, Germany, and ${ }^{2}$ Department of Molecular \\ Neurobiology and Center for the Molecular Physiology of the Brain, Max Planck Institute of Experimental Medicine, 37075 Göttingen, Germany
}

Complexins (Cplxs) are SNARE complex regulators controlling the speed and $\mathrm{Ca}^{2+}$ sensitivity of SNARE-mediated synaptic vesicle fusion. We have shown previously that photoreceptor ribbon synapses in mouse retina are equipped with $\mathrm{Cplx} 3$ and $\mathrm{Cplx} 4$ and that lack of both Cplxs perturbs photoreceptor ribbon synaptic function; however, Cplx3/4 function in photoreceptor synaptic transmission remained elusive. To investigate $\mathrm{Cplx} 3 / 4$ function in photoreceptor ribbon synapses, voltage-clamp recordings from postsynaptic horizontal cells were performed in horizontal slice preparations of Cplx $3 / 4$ wild-type (WT) and Cplx3/4 double knock-out (DK0) mice. We measured tonic activity in light and dark, current responses to changes in luminous intensity, and electrically evoked postsynaptic responses. Cplx $3 / 4$ decreased the frequency of tonic events and shifted their amplitude distribution to smaller values. Light responses were sustained in the presence of $\mathrm{Cplx} 3 / 4$, but transient in their absence. Finally, Cplx3/4 increased synaptic vesicle release evoked by electrical stimulation. Using electron microscopy, we quantified the number of synaptic vesicles at presynaptic ribbons after light or dark adaptation. In Cplx $3 / 4$ WT photoreceptors, the number of synaptic vesicles associated with the ribbon base close to the release site was significantly lower in light than in dark. This is in contrast to Cplx3/4 DKO photoreceptors, in which the number of ribbon-associated synaptic vesicles remained unchanged regardless of the adaptational state. Our results indicate a suppressing and a facilitating action of $\mathrm{Cplx} 3 / 4$ on $\mathrm{Ca}^{2+}$-dependent tonic and evoked neurotransmitter release, respectively, and a regulatory role in the adaptation-dependent availability of synaptic vesicles for release at photoreceptor ribbon synapses.

\section{Significance Statement}

Synaptic vesicle fusion at active zones of chemical synapses is executed by SNARE complexes. Complexins (Cplxs) are SNARE complex regulators and photoreceptor ribbon synapses are equipped with Cplx 3 and Cplx4. The absence of both Cplxs perturbs ribbon synaptic function. Because we lack information on Cplx function in photoreceptor synaptic transmission, we investigated Cplx function using voltage-clamp recordings from postsynaptic horizontal cells of $\mathrm{Cplx} 3 / 4$ wild-type and $\mathrm{Cplx} 3 / 4$ double knockout mice and quantified synaptic vesicle number at the ribbon after light and dark adaptation using electron microscopy. The findings reveal a suppressing action of $\mathrm{Cplx} 3 / 4$ on tonic neurotransmitter release, a facilitating action on evoked release, and a regulatory role of $\mathrm{Cplx} 3 / 4$ in the adaptation-dependent availability of synaptic vesicles at mouse photoreceptor ribbon synapses.

\section{Introduction}

The architecture of the active zone in presynaptic nerve terminals reflects the specific functional needs of a given synapse (Zhai and

Received Dec. 3, 2015; revised May 6, 2016; accepted May 10, 2016.

Author contributions: A.F. and J.H.B. designed research; N. Babai, A.S., H.R.-L., M.F., and J.M. performed research; N. Babai, A.S., H.R.-L., M.F., J.M., K.R., N. Brose, and J.H.B. analyzed data; A.F. and J.H.B. wrote the paper.

This work was supported by the Deutsche Forschungsgemeinschaft (DFG Grant BR 1643/5-1 to J.H.B.). We thank Nadja Schröder and Andrea Nerz for excellent technical assistance.

The authors declare no competing financial interests.

Correspondence should be addressed to either of the following: Dr. Johann Helmut Brandstätter or Dr. Andreas Feigenspan, Department of Biology, Animal Physiology, FAU Erlangen-Nürnberg, Staudtstr. 5, 91058 Erlangen, Germany. E-mail: johann.helmut.brandstaetter@fau.de or andreas.feigenspan@fau.de.
Bellen, 2004; Matthews and Fuchs, 2010; Gundelfinger and Fejtová, 2012). The photoreceptors of the retina transmit light signals over a wide, dynamic range of intensities. For this purpose, they use graded potentials and optimize information transfer by continuously adjusting their synaptic output to a changing input. This requires exocytosis of large numbers of synaptic vesicles at high rates. To accommodate high release rates, photoreceptor ribbon synapses are equipped with a specialized electron-dense, plate-like organelle, the presynaptic ribbon. Anchored to the arciform density in close vicinity to voltage-gated $\mathrm{Ca}^{2+}$ channels, 
the ribbon tethers some 100 synaptic vesicles (Thoreson et al., 2004; Sterling and Matthews, 2005; tom Dieck et al., 2005; tom Dieck and Brandstätter, 2006; Heidelberger, 2007; Regus-Leidig and Brandstätter, 2012).

It is generally assumed that unique molecular constituents facilitate the extraordinary performance of photoreceptor ribbon synapses. Such constituents include the ribbon synapse specific proteins RIBEYE (Schmitz et al., 2000; Maxeiner et al., 2016) and Piccolino (Regus-Leidig et al., 2013, 2014a), the active zone protein ubMunc13-2 (Cooper et al., 2012), and Cplx3 and Cplx4 (Reim et al., 2005). Conventional chemical synapses contain the essential SNARE regulators Cplx1 and Cplx2 (Reim et al., 2001; Brose, 2008). In co-sedimentation assays, we demonstrated that Cplx3 and Cplx4 bind the SNARE complex, albeit with lower binding affinity than Cplx1 or Cplx2 (Reim et al., 2005). Electroretinographic (ERG) recordings from mice lacking Cplx $3 / 4$ indicated altered synaptic transmission at photoreceptor ribbon synapses (Reim et al., 2009).

Recently, the role of Cplx3 in mouse rod bipolar cell ribbon synapses, which only contain Cplx3, was examined by peptidebased perturbation of Cplx 3 function. The results of this study suggest a dual role of Cplx3 as a brake on the SNARE complex that prevents spontaneous fusion in the absence of $\mathrm{Ca}^{2+}$ influx and as a facilitator of transmitter release evoked by depolarization (Vaithianathan et al., 2015).

In the present study, we investigated the function of $\mathrm{Cplx} 3$ and Cplx4 at the cone photoreceptor ribbon synapse using voltageclamp recordings from postsynaptic horizontal cells $(\mathrm{HCs})$ in a slice preparation of Cplx3/4 wild-type (WT) and Cplx3/4 double knockout (DKO) mice. We found that Cplx $3 / 4$ suppresses tonic activity and shapes the light response kinetics of HCs while at the same time facilitating $\mathrm{HC}$ responses evoked by electrical stimulation of photoreceptors. These results are in agreement with the dual role of Cplx3 reported in mouse rod bipolar cell ribbon synapses (Vaithianathan et al., 2015). Interestingly, regardless of the adaptational state of photoreceptors, the number of ribbon-associated synaptic vesicles remained unchanged in the Cplx3/4 DKO. This is in contrast to the Cplx3/4 WT situation, where the number of vesicles associated with the ribbon base close to the release site was significantly lower in light than in dark. These findings indicate a novel regulatory role of Cplx3/4 in the adaptation-dependent availability of synaptic vesicles for release at mouse photoreceptor ribbon synapses.

\section{Materials and Methods}

Ethics statement. All experiments were performed in compliance with the guidelines for the welfare of experimental animals issued by the Federal Government of Germany and the University of Erlangen-Nürnberg.

Animals and light regime. Adult (2-3 months of age) mice [Cplx $3 / 4$ WT, Cplx3/4 DKO, C57BL/6JRj (BL/6), and Tg(Rac3-EGFP)JZ58Gsat/ Mmcd (Rac3-EGFP)] and adult (2-3 months of age) rats (Dark Agouti) of either sex were used in this study. The animals were kept in a $12 \mathrm{~h} / 12 \mathrm{~h}$ light/dark cycle with lights on at 6:00 A.M. and an average illumination of 200 lux (white light; TLD 58W/25 tubes; Philips). Light and dark adaptation was performed as follows: The animals were killed during the regular diurnal cycle either $3 \mathrm{~h}$ after light onset (9:00 A.M.) or $3 \mathrm{~h}$ after light offset (9:00 P.M.). Furthermore, BL/6 mice that were dark or light adapted for $3 \mathrm{~h}$ and then exposed to different periods of light (200 lux, white light) or dark (1 min, $10 \mathrm{~min}$, or $15 \mathrm{~min}$ ) were studied.

Horizontal slice preparation and electrophysiology. The preparation of horizontal retinal slices was described previously (Feigenspan and Babai, 2015). Briefly, the retina was isolated, cut into small pieces, and embedded in $1.8 \%$ low-melting agarose dissolved in Ames' medium (SigmaAldrich). Then, $160-\mu \mathrm{m}$-thick horizontal slices were cut with a vibratome (Leica Microsystems). Variable quality of slices and alterations in the plane of sectioning might introduce cell-to-cell variability in electrophysiological recordings. After sectioning, slices were kept in Ames' medium at $37^{\circ} \mathrm{C}, \mathrm{pH} 7.2$, in an atmosphere containing $5 \% \mathrm{CO}_{2}$ and $55 \% \mathrm{O}_{2}$. Whole-cell recordings were performed at room temperature (RT; $\left.22-24^{\circ} \mathrm{C}\right)$. HCs were visualized with a $63 \times$ water-immersion objective (Zeiss) using a fixed-stage microscope (Zeiss Axio Examiner) equipped with Dodt contrast. Currents were recorded with an EPC-10 patch-clamp amplifier (Heka Elektronik), low-pass filtered at $2.9 \mathrm{kHz}$ using a built-in Bessel filter, and digitized at $10 \mathrm{kHz}$ with Patchmaster software (Heka Elektronik). The extracellular solution contained the following (in mM): $137 \mathrm{NaCl}, 5.4 \mathrm{KCl}, 1.8 \mathrm{CaCl}_{2}, 1 \mathrm{MgCl}_{2}, 5$ HEPES, 10 glucose, $\mathrm{pH}$ 7.4. The intracellular pipette solution contained the following (in mM): $120 \mathrm{~K}$-D-gluconate, $20 \mathrm{KCl}, 1 \mathrm{CaCl}_{2}, 2 \mathrm{MgCl}_{2}, 11 \mathrm{EGTA}, 10$ HEPES, $\mathrm{pH}$ 7.2, for $\mathrm{HCs}$ and 136.6 caesium gluconate, $13 \mathrm{TEACl}$, 4 MgATP, 0.4 NaGTP, 5 EGTA, 15 HEPES, pH 7.2, for cone photoreceptors.

To trigger synaptic responses between cone photoreceptors and HCs, light and electrical stimulation were used. For light stimulation, full-field flashes of $1300 \mathrm{~W} / \mathrm{cm}^{2}$ irradiance were applied using the xenon arc lamp of the Lambda DG 4 illumination system (Sutter Instruments) as the light source. Band-pass-filtered light $(470 \pm 40 \mathrm{~nm})$ was transmitted to the retinal tissue via fiber optics and the objective lens of the microscope. Patch electrodes were pulled from borosilicate glass (Sutter Instruments) to a final resistance of 7-10 M $\Omega$. Electrode tips were coated with Sylgard 184 (Dow-Corning) and their series resistance (10-30 M $\Omega$ ) was compensated up to $60 \%$

For electrical stimulation, brief electrical pulses (1-15 V, $1 \mathrm{~ms})$ were applied with an isolated pulse stimulator (A-M Systems, model 2100) through a platinum-iridium bipolar stimulation electrode (Science Products). The stimulation electrode was positioned in close vicinity of a $\mathrm{HC}$ body, where it was slightly touching the surface of the retinal slice. A position was chosen that elicited maximal postsynaptic responses in the HC. Generally, artifacts caused by electrical stimulation were observed in the rising phase of the EPSCs, but did not interfere with the detection of peak amplitudes. Very strong electrical stimulation was avoided because of electrolysis on the surface of the stimulation electrode.

Cyclothiazide (Sigma-Aldrich) was prepared as a $100 \mathrm{~mm}$ stock solution in DMSO and diluted to a final concentration of $100 \mu \mathrm{M} . \mathrm{CdCl}_{2}$ (Sigma-Aldrich) was dissolved in distilled water (10 mM stock solution) and diluted to a final concentration of $100 \mu \mathrm{M}$. All drugs were applied in extracellular solution directly to the recorded $\mathrm{HC}$ with a focal pressurized perfusion system (ALA Scientific Instruments). The two-way solenoid valves were controlled by Patchmaster data acquisition software (Heka Elektronik), leading to complete solution exchange in the vicinity of the cell within $100-200 \mathrm{~ms}$.

Data were analyzed with Fitmaster (Heka Elektronik), Origin (Microcal), MATLAB (The MathWorks), and Igor Pro version 6.1 (Wave Metrics) software. The analysis of EPSCs was performed with MiniAnalysis software (Synaptosoft). For each event, the baseline was adjusted to account for fluctuations in holding current. Double peaks or other complex waveforms were not analyzed. The threshold for event detection was set to twice the SD of baseline noise (typically 1.2-1.8 pA). In addition, only events with rise times faster than $1.5 \mathrm{~ms}$ were considered for analysis. Rise time was measured as the time between $10 \%$ and $90 \%$ of peak amplitude.

Data are reported as mean \pm SEM and $n$ indicates the number of cells measured. Comparison of means was performed using Student's $t$ test or Mann-Whitney $U$ test with $p$-values as indicated; equality of variances was assessed with Levene's test. Statistical analysis was performed with Systat version 13. For illustration purposes, current traces were low-pass filtered at $1 \mathrm{kHz}$.

Qualitative fluorescence $\mathrm{Ca}^{2+}$ measurements. Retinal slices were cut 200 $\mu \mathrm{m}$ thick with a vibratome (Leica) and incubated with $2 \mu \mathrm{m}$ Fluo-4-AM (Invitrogen) in Ames' medium (Sigma-Aldrich) at RT for $20 \mathrm{~min}$, followed by a $20 \mathrm{~min}$ incubation in extracellular solution continuously oxygenated with $95 \% \mathrm{O}_{2}$ and $5 \% \mathrm{CO}_{2}, \mathrm{pH} 7.4$. Retinal slices were perfused with extracellular solution at a speed of $\sim 1 \mathrm{ml} / \mathrm{min}$. Fluorescence images were acquired using a fixed-stage microscope (Zeiss Axio Examiner) with a $20 \times$ water-immersion objective (Zeiss), a Zeiss $38 \mathrm{HE}$ filter set (470 $\pm 40 \mathrm{~nm}$ excitation, $525 \pm 50 \mathrm{~nm}$ emission), and an AxioCam 
A

Cplx3/4WT

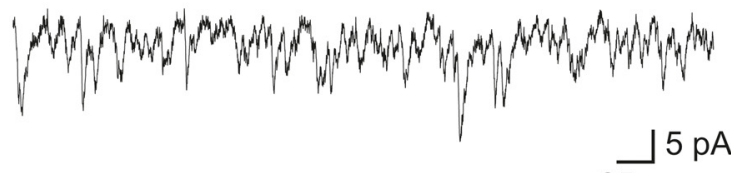

C

Cplx3/4WT

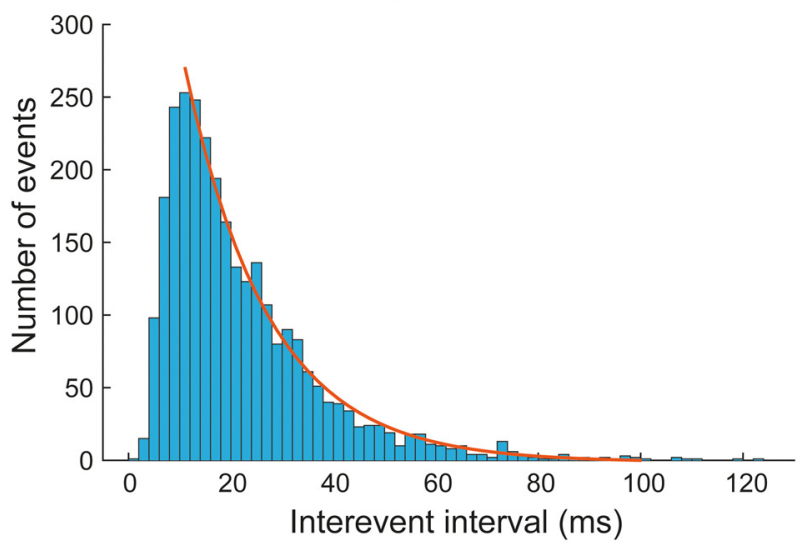

E

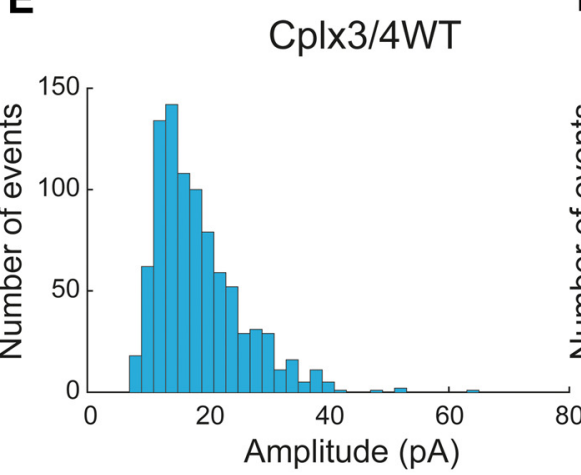

F
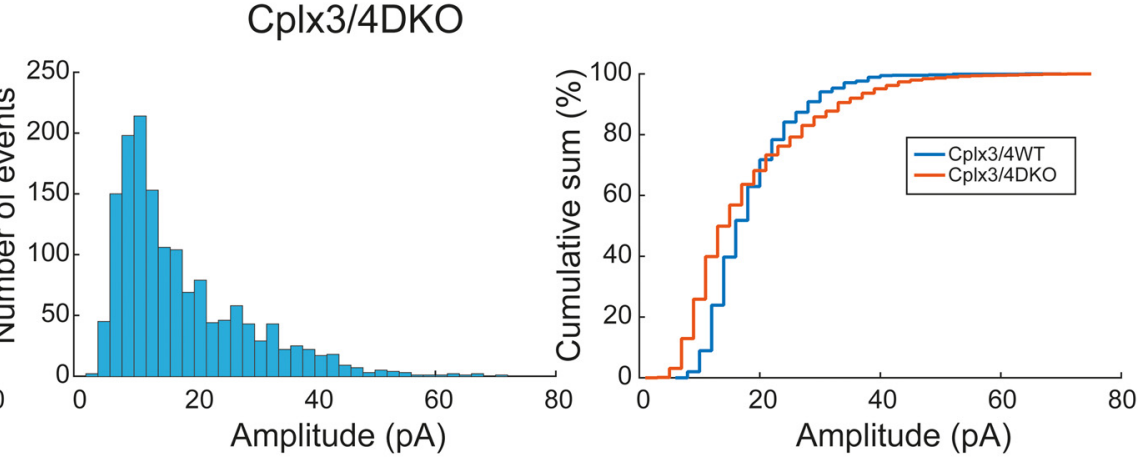

H

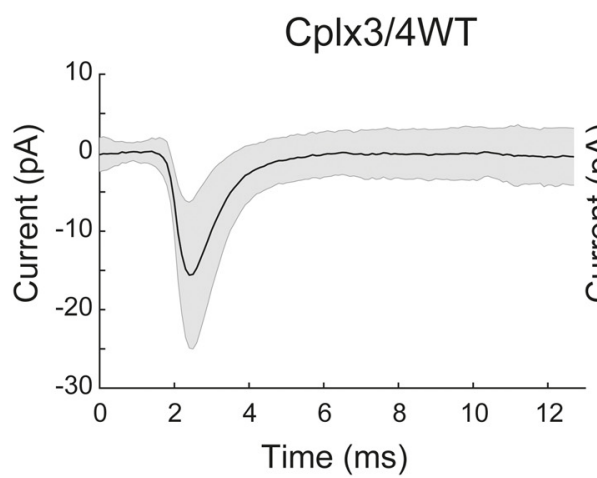

B

\section{Cplx3/4DKO}
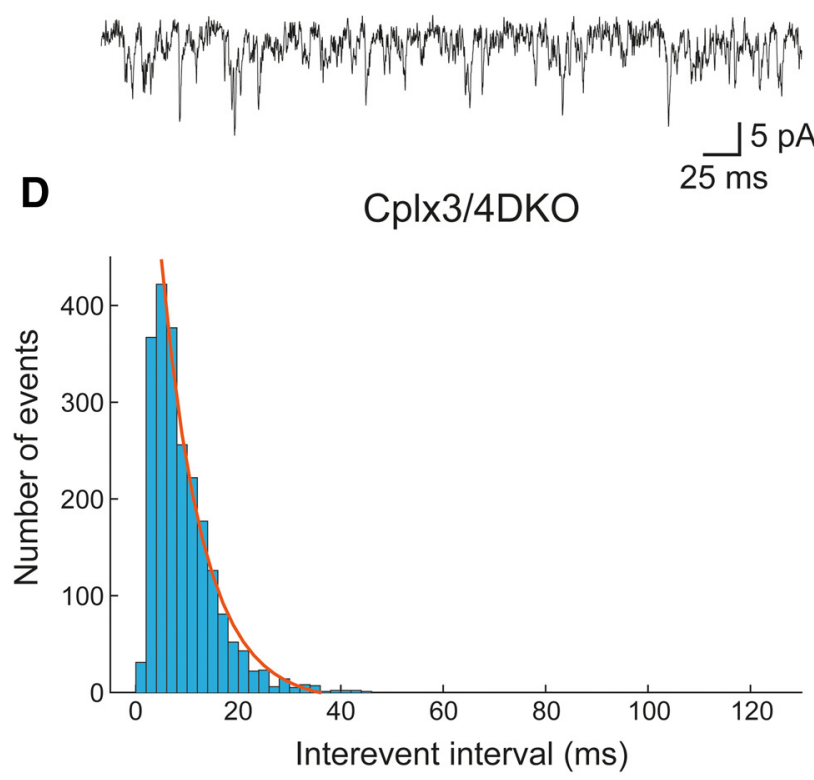

G

J

Cplx3/4DKO
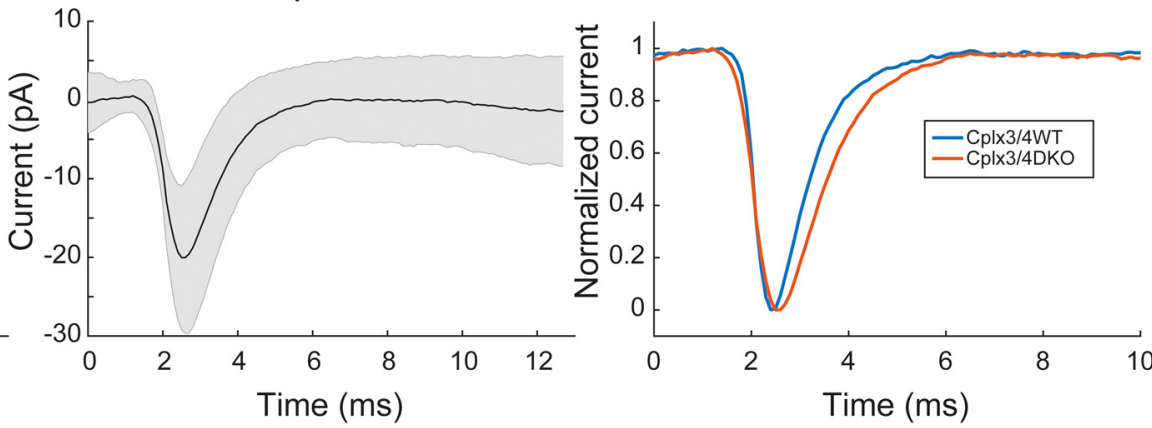

Figure 1. Horizontal cell activity in Cplx3/4 WT and Cplx3/4 DK0 mouse retinas. $A, B$, EPSCs recorded at $-60 \mathrm{mV}$ holding potential from a horizontal cell body in a slice preparation of a Cplx3/4 WT (A) and a Cplx3/4 DKO (B) retina. $\boldsymbol{C}, \boldsymbol{D}$, Interevent interval histograms of EPSCs recorded from horizontal cells of Cplx3/4 WT (C) and (plx3/4 DKO (D) retinas. Histograms were fitted each with a single-exponential function as indicated by the solid lines. Parameters derived from the fits were $A_{\mathrm{WT}}=532, \tau_{\mathrm{WT}}=11.35 \pm 0.30 \mathrm{~ms}\left(R^{2}=0.9911, n=2829\right)$ and $A_{\mathrm{DK} 0}=850, \tau_{\mathrm{DK} 0}=5.56 \pm 0.32 \mathrm{~ms}\left(R^{2}=0.98797, n=2271\right)$. Bin width $=2 \mathrm{~ms} . E, F$, Amplitude histograms were constructed from individual EPSCs recorded from Cplx3/4 WT $(\boldsymbol{E})$ and $(\mathrm{p} \mid x 3 / 4$ DKO $(\boldsymbol{F})$ retinas. Bin width $=2 \mathrm{pA}$. G, Amplitude distribution of EPSCs plotted as cumulative sum for Cplx3/4 WT and Cplx3/4 DKO mouse retinas. Bin width $=2$ pA. $\boldsymbol{H}$, Average EPSC from (plx3/4 WT ( $n=655$ events, 3 cells). I, Average EPSC from CpIx3/4 DKO ( $n=908,6$ cells). Shaded areas in $\boldsymbol{G}$ and $\boldsymbol{H}$ indicate \pm 1 SD. J, 0verlay of normalized average EPSCs from Cplx3/4 WT and Cplx3/4 DKO. 

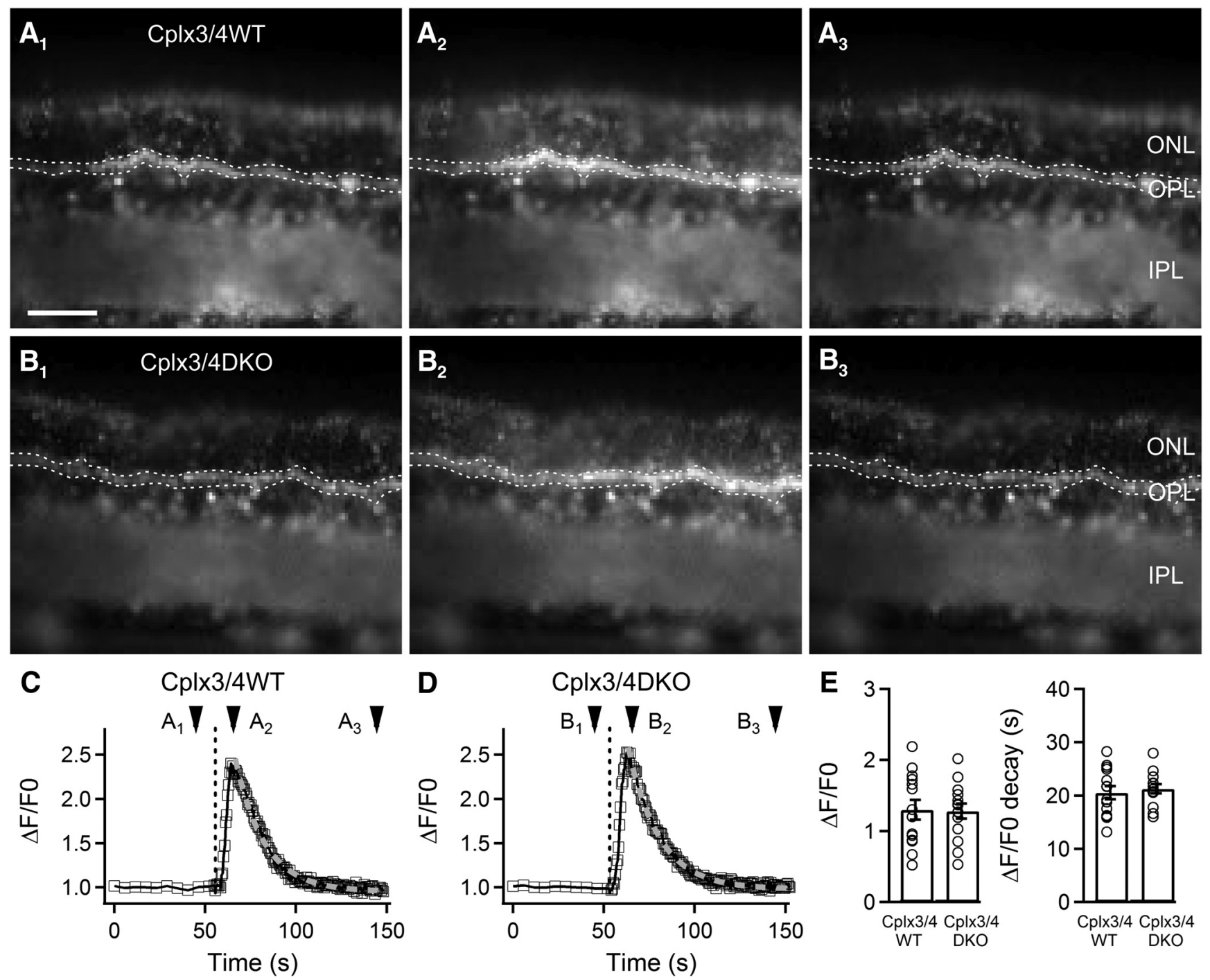

Figure 2. Qualitative fluorescence $\mathrm{Ca}^{2+}$ measurements. $\boldsymbol{A}, \boldsymbol{B}$, Images of vertical slices from Cplx3/4 WT $(\boldsymbol{A})$ and $\mathrm{Cplx3/4}$ DK0 $(\boldsymbol{B})$ retinas loaded with $2 \mu \mathrm{m}$ Fluo4-AM before $(\boldsymbol{A} \mathbf{1}, \boldsymbol{B} 1)$, during $(\boldsymbol{A} \mathbf{2}$, $B 2)$, and after $(\boldsymbol{A} \mathbf{B}, \boldsymbol{B} 3)$ application of a $150 \mathrm{~mm} \mathrm{KCl}$ puff $(1 \mathrm{~s})$. The regions enclosed in dotted lines mark the sampling areas for the $\mathrm{Ca}^{2+}$ measurements. $\boldsymbol{C}, \boldsymbol{D}$, Monitoring changes of $C \mathrm{C}^{2+}$ levels in Cplx3/4 WT (C) and Cplx3/4 DKO (D) photoreceptor terminals. The vertical dashed line marks the start of the KCl puff. Arrowheads refer to images shown in $\boldsymbol{A}$ and $\boldsymbol{B}$. $\boldsymbol{E}$, Relative changes in peak fluorescence and in fluorescence decay were not significantly different between the two genotypes. ONL, Outer nuclear layer; OPL, outer plexiform layer; IPL, inner plexiform layer. Scale bar in $\boldsymbol{A}$ applies to $A$ and $B, 50 \mu \mathrm{m}$.

HSm digital camera (Zeiss). Excitation, emission, and data analysis were controlled and picture acquisition was performed with AxioVision 4.8 software (Zeiss). To evoke $\mathrm{Ca}^{2+}$ responses, $\mathrm{KCl}(150 \mathrm{~mm})$ was applied focally for $1 \mathrm{~s}$ to the outer plexiform layer with a pressurized perfusion system (ALA Scientific Instruments). $\mathrm{Ca}^{2+}$ changes were recorded as alterations in relative fluorescence with $450 \mathrm{~ms}$ exposure time every $5 \mathrm{~s}$ before and after application of $\mathrm{KCl}$. Cell-free background signals were subtracted from each image and then ratios $\left(\mathrm{d} F / F_{0}\right)$ were calculated with the initial image as a reference $\left(F_{0}\right)$. Time-dependent changes in relative fluorescence intensity were determined for defined regions of interest in the outer plexiform layer.

Tissue preparation and light microscopic immunocytochemistry. Preparation of retinal tissue and antibody incubation for light microscopic immunocytochemistry were done as described previously (Reim et al., 2005). Briefly, the eyes were opened and retinas were immersion fixed in the eyecup for $15 \mathrm{~min}$ in $4 \%$ paraformaldehyde in phosphate buffer (PB; $0.1 \mathrm{M}, \mathrm{pH}$ 7.4). The retinas were mounted in freezing medium (ReichertJung) and $12-\mu \mathrm{m}$-thick horizontal sections were cut with a cryostat (Leica CM3050 S). Primary antibody incubation was performed overnight at RT and secondary antibody incubation for $1 \mathrm{~h}$ at RT. Labeled sections were examined with a confocal laser scanning microscope (LSM
710; Zeiss) or an Olympus IX83 with a two-color STED 775 QUAD scanning unit (Abberior Instruments). Confocal images were adjusted for contrast and brightness using Adobe Photoshop CS6. STED images were deconvolved with ImageJ. The following primary and secondary antibodies were used: monoclonal mouse anti-GluA2 (1:1000; BD Biosciences), polyclonal rabbit anti-Cacnalf (Pep3; 1:3000; Specht et al., 2009; Regus-Leidig et al., 2014b), rabbit anti-Calbindin (1:1000; Swant), guinea pig anti-Piccolo (1:5000; Synaptic Systems), Alexa Fluor 488/594conjugated goat anti-mouse IgG (1:500; Invitrogen), Atto647Nconjugated goat anti-rabbit IgG (1:100; Sigma-Aldrich), Cy3-conjugated goat anti-rabbit IgG (1:200; Dianova), and Cy5-conjugated goat antiguinea pig IgG (1:100; Dianova). Cone photoreceptors were labeled with fluorescein-conjugated peanut agglutinin (PNA; 1:500; Vector Laboratories).

Tissue preparation and quantitative electron microscopy. For good tissue preservation, retinas were fixed in $4 \%$ paraformaldehyde and $2.5 \%$ glutaraldehyde for $2 \mathrm{~h}$ at RT. Tissue contrasting was performed by incubation in $1.5 \%$ potassium ferrocyanide and $2 \%$ osmium tetroxide in cacodylate buffer for $1.5 \mathrm{~h}$. Retinal tissue was dehydrated with an ethanol series and propylene oxide with $0.5 \%$ uranyl acetate added at the $70 \%$ ethanol step, before embedding in Renlam resin (Serva). Ultrathin sec- 


\section{A $\quad$ Cplx3/4WT}
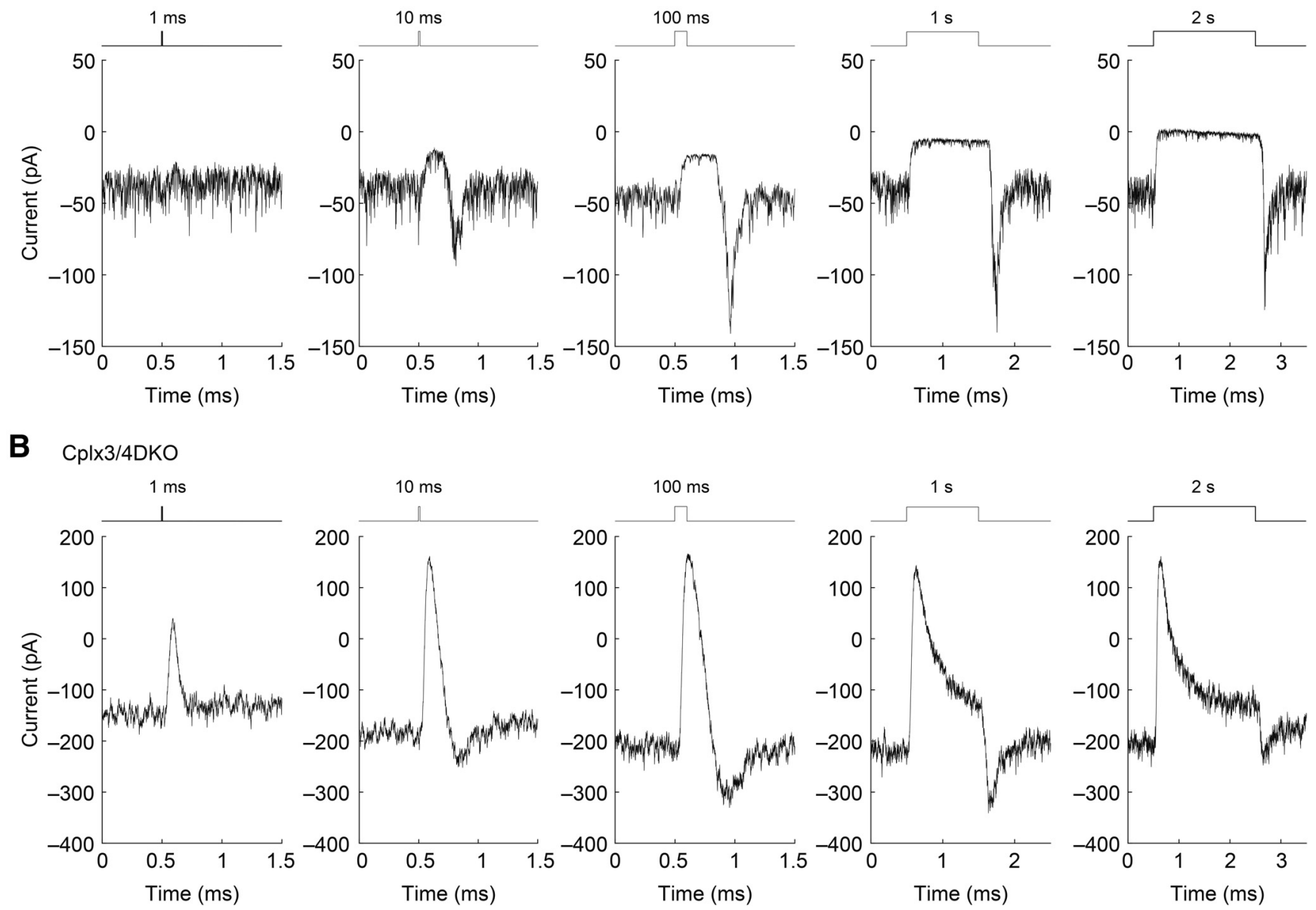

Figure 3. Horizontal cell light responses in Cplx3/4 WT and Cplx3/4 DKO mouse retinas. A, Response of relatively dark-adapted horizontal cells from Cplx3/4 WT retina to full-field stimulation $(15,000 \mathrm{~lx})$ of increasing duration. Upward and downward deflections of stimulus traces reflect onset and offset of light, respectively, whereas the duration of the stimulus is indicated above each trace. Holding potential: $-60 \mathrm{mV}$. B, Response of horizontal cells from Cplx3/4 DKO retina to full-field stimulation of identical intensity and duration. Holding potential: $-60 \mathrm{mV}$.

tions $(60 \mathrm{~nm})$ were stained with uranyl acetate and lead citrate and examined using a Zeiss EM10 electron microscope. Images were taken with a Gatan SC1000 Orius TM CCD camera in combination with the Digital Micrograph TM software (Gatan). Images were adjusted for contrast and brightness using Adobe Photoshop CS5.

For each experimental condition, we prepared random ultrathin sections of retinas from three mice and examined between 100 and 300 rod and cone photoreceptor terminals. For the analysis of the number of ribbon-associated vesicles in single ultrathin sections, we chose only photoreceptor ribbon synaptic complexes with a rod-shaped presynaptic ribbon and with both the arciform density and the triadic arrangement of the invaginating postsynaptic elements visible in the section plane. The first row of vesicles $(\sim 30 \mathrm{~nm}$ distance to the ribbon) along the entire height of the ribbon and within the basal $100 \mathrm{~nm}$ of the ribbon was counted in single sections.

\section{Results}

\section{Lack of Cplx3 and Cplx4 affects HC tonic activity}

HCs display tonic postsynaptic activity in the dark, which is caused by the release of glutamate from photoreceptors (Feigenspan and Babai, 2015). These EPSCs occur spontaneously under dark-adapted conditions and are most likely driven by entry of calcium $\left(\mathrm{Ca}^{2+}\right)$ into tonically depolarized photoreceptors. We will refer to these currents as baseline EPSCs to distinguish them from EPSCs evoked by electrical stimulation.
To investigate whether this activity is affected by the Cplx3/4 DKO, we performed patch-clamp recordings from $\mathrm{HC}$ bodies in Cplx3/4 DKO mice under relatively darkadapted conditions in dim red light. At a holding potential of $-60 \mathrm{mV}$, HCs recorded from Cplx3/4 WT and Cplx3/4 DKO mice showed EPSCs (Fig. 1A,B), many of which displayed a monophasic waveform characterized by a fast rising phase and a monoexponential decay. More complex events consisting of multiple peaks occurred frequently, but were not considered for analysis. Eighty to $90 \%$ of all synaptic events under darkadapted conditions showed a complex current trajectory; the percentage of complex events did not differ between Cplx3/4 WT and Cplx3/4 DKO animals.

The frequency of baseline EPSCs as determined from interevent intervals was significantly increased in Cplx3/4 DKO mice ( $p<0.0001$, Mann-Whitney $U$ test). Interevent intervals ranged from 2.9 to $122.4 \mathrm{~ms}$ (median, $17.5 \mathrm{~ms}$; coefficient of variation, $0.7, n=2829$ ) in Cplx3/4 WT and from 1 to 45.5 $\mathrm{ms}$ (median, $7.5 \mathrm{~ms}$; coefficient of variation, $0.67 ; n=2247$ ) in Cplx3/4 DKO mice. Comparing individual cells from both Cplx3/4 WT and Cplx3/4 DKO animals also revealed significant differences. Corresponding histograms of interevent intervals were fitted with a monoexponential function charac- 


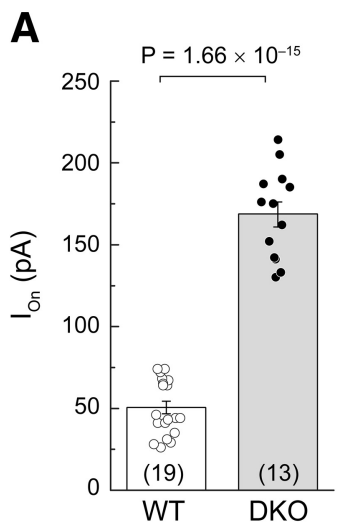

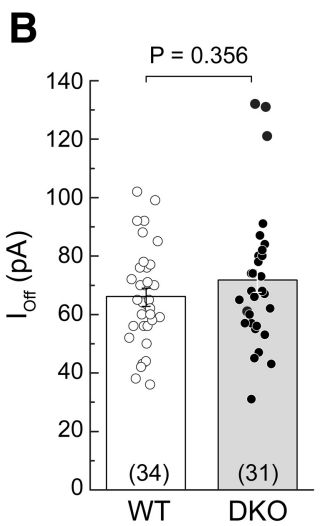
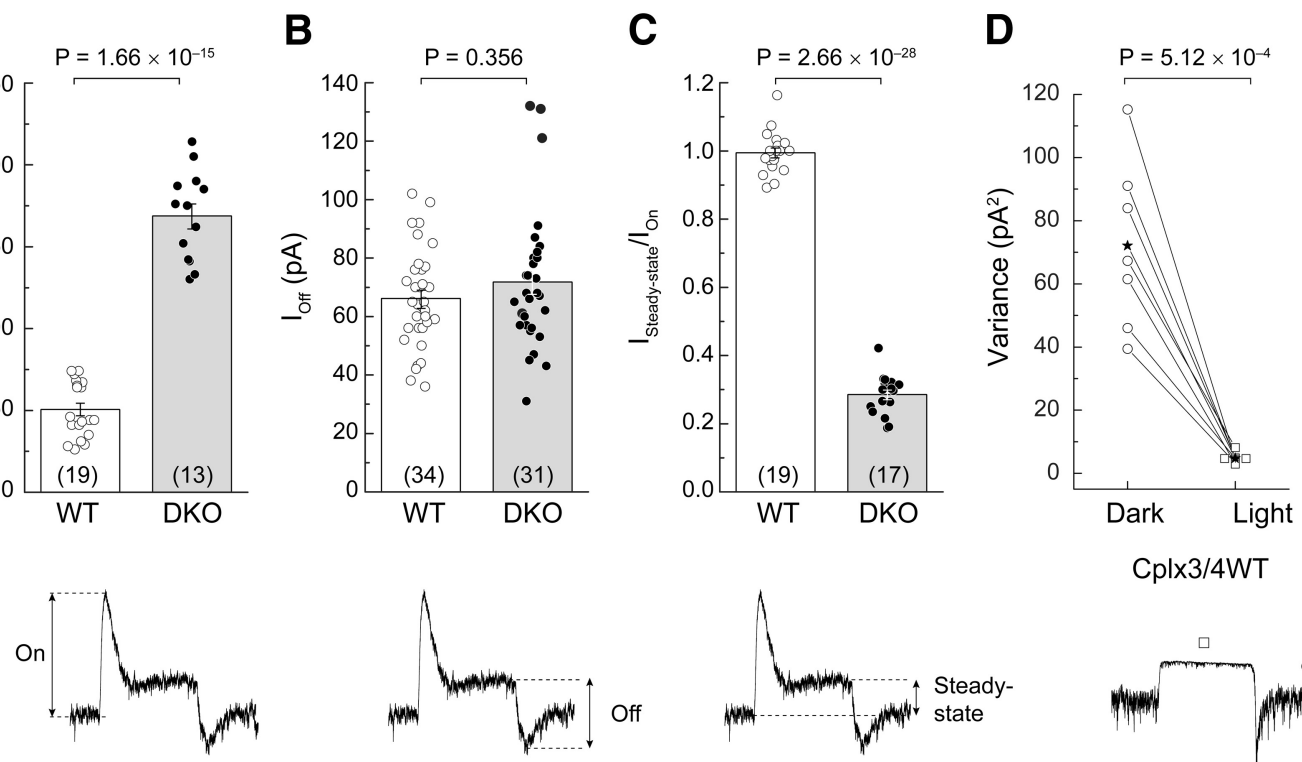

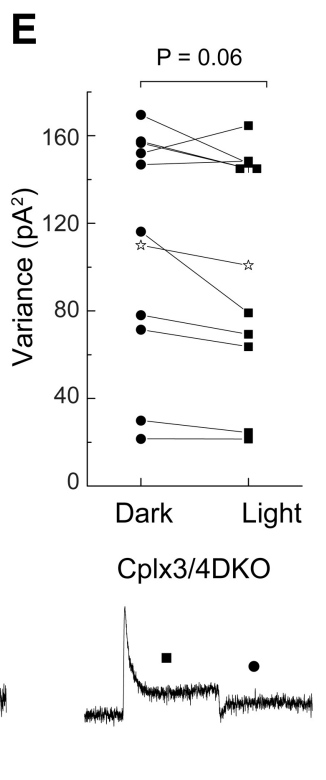

Figure 4. Comparison of horizontal cell light responses from Cplx3/4 WT and Cplx3/4 DK0 mouse retinas. $A$, Combined bar graph and scatter plot of peak amplitudes measured at light onset corresponding to the inhibition of tonic inward current. Values differ significantly ( $t$ test). $\boldsymbol{B}$, Combined bar graph and scatter plot of peak amplitudes measured at light offset. Values do not differ significantly ( $t$ test). $C$, Combined bar graph and scatter plot of current ratios measured under steady-state conditions $\left(I_{\text {steady-state }}\right)$ and at light onset $\left(I_{0 \mathrm{~N}}\right)$. Values differed significantly ( $t$ test). D, Pairwise plot of current variance measured in dark and light for horizontal cells from (plx3/4 WT retina. Values differ significantly (paired $t$ test). $E$, Pairwise plot of variance measured in dark and light for horizontal cells from (plx3/4 DKO retina. Values differ significantly (paired $t$ test). Asterisks in $\boldsymbol{D}$ and $\boldsymbol{E}$ indicate arithmetic mean. Some data points are plotted horizontally for clarity. Numbers in parentheses in $\boldsymbol{A}-\boldsymbol{C}$ denote the number of observations. $p$-values are given above the plots. Parameters for measurements are exemplified below for Cplx3/4 DK0 current traces.

terized by time constants of 11.35 and $5.56 \mathrm{~ms}$ for Cplx3/4 WT and Cplx3/4 DKO mice, respectively (Fig. 1C,D).

Individual monophasic events were assessed with respect to peak amplitude, $10-90 \%$ rise time, and time constant of decay. As described previously (Feigenspan and Babai, 2015), the amplitudes of Cplx3/4 WT baseline EPSCs ranged from 7.7 to $64.8 \mathrm{pA}$ (median, $16.6 \mathrm{pA}$; coefficient of variation, $0.39 ; n=$ 896 events), whereas in Cplx3/4 DKO mice, peak amplitudes covered the range from 3.7 to $71.5 \mathrm{pA}$ with a median value of $14.0 \mathrm{pA}$ (coefficient of variation, $0.61 ; n=1527$ events; Fig. $1 E, F)$. Although both amplitude distributions displayed a peak at $\sim 12 \mathrm{pA}$, the amplitude distribution appeared broader in Cplx3/4 DKO mice (Fig. $1 F$ ). The variance of both distributions was significantly different $\left(p=3.97 \times 10^{-40}\right.$, Levene test). The cumulative sum of the amplitude distribution revealed a higher percentage of small amplitude events $(<20$ $\mathrm{pA}$ ), as well as a larger number of amplitudes $>30 \mathrm{pA}$ (Fig. $1 G)$. Therefore, the distributions differed significantly $(p=$ $2.88 \times 10^{-13}$, Mann-Whitney $U$ test).

In Cplx3/4 DKO mice, $10-90 \%$ rise times ranged from 0.2 to $1.36 \mathrm{~ms}$ with a median value of $0.69 \mathrm{~ms}$ (coefficient of variation, $0.33 ; n=512$ events; data not shown). Compared with Cplx3/4 WT mice, the distribution was significantly shifted toward longer durations $\left(p=1.91 \times 10^{-23}\right.$, MannWhitney $U$ test $)$. Time constants of decay $\left(\tau_{\text {decay }}\right)$ were determined by fitting a first-order exponential function to the decaying phase of each monophasic baseline EPSCs. In Cplx3/4 DKO mice, $\tau_{\text {decay }}$ ranged from 0.25 to $4.09 \mathrm{~ms}$ (coefficient of variation, 0.49 ; median, $0.943 \mathrm{~ms} ; n=512$; data not shown). Compared with Cplx3/4 WT mice, the distribution of decay times was shifted toward longer durations $(p=1.08 \times$ $10^{-6}$, Mann-Whitney $U$ test).

Individual baseline EPSCs from Cplx3/4 WT and Cplx3/4 DKO were aligned to $50 \%$ rise time and averaged (Fig. $1 H, I$ ).
Whereas variability of peak amplitudes caused the SD at $\sim 2$ $\mathrm{ms}$, the occurrence of successive events at random times and with varying amplitudes was responsible for the scatter around baseline. The higher frequency of baseline EPSCs in Cplx3/4 DKO was therefore indirectly apparent in the larger SD after the peak amplitude. The variance of peak amplitudes was $40.35 \mathrm{pA}^{2}$ in Cplx3/4 WT and $61.37 \mathrm{pA}^{2}$ in Cplx3/4 DKO. During baseline measured at $12 \mathrm{~ms}$, variances were $12.92 \mathrm{pA}^{2}$ and $25.97 \mathrm{pA}^{2}$ for Cplx3/4 WT and Cplx3/4 DKO. The differences in variance between both genotypes differed significantly at peak amplitudes and during baseline $(p=$ $1.48 \times 10^{-5}$ for peak and $p=3.72 \times 10^{-13}$ for baseline, Levene's test).

Normalization of mean baseline EPSCs to values between 0 and 1 revealed the different kinetics described above with slower rise and decay time in Cplx3/4 DKO mice (Fig. $1 J$ ). In summary, the absence of Cplx3 and Cplx4 significantly changed the distribution of amplitudes, kinetics, and frequency of excitatory currents measured in HC bodies.

\section{Lack of Cplx3 and Cplx4 does not affect $\mathrm{Ca}^{2+}$ levels in photoreceptor terminals}

Synaptic release is triggered by $\mathrm{Ca}^{2+}$ influx into synaptic terminals through voltage-gated $\mathrm{Ca}^{2+}$ channels. To test whether the altered amplitudes, kinetics, and frequency of HC activity in Cplx3/4 DKO mice can be attributed to altered levels of $\mathrm{Ca}^{2+}$ in Cplx3/4 DKO photoreceptor terminals, we performed qualitative $\mathrm{Ca}^{2+}$ imaging (Fluo-4-AM; $K_{\mathrm{d}}=345 \mathrm{nM}$; Gee et al., 2000). Retinal slices were loaded with $2 \mu \mathrm{M}$ Fluo4-AM and relative changes in intraterminal $\mathrm{Ca}^{2+}$ levels were monitored before, during, and after a strong depolarizing stimulus $(150 \mathrm{~mm} \mathrm{KCl,} 1 \mathrm{~s}$ duration; Fig. 2A,B). Comparison of Cplx3/4 WT and Cplx3/4 DKO photoreceptor terminals showed no significant differences in depolarization-induced changes of $\mathrm{Ca}^{2+}$ levels and time con- 
A

Cplx3/4WT

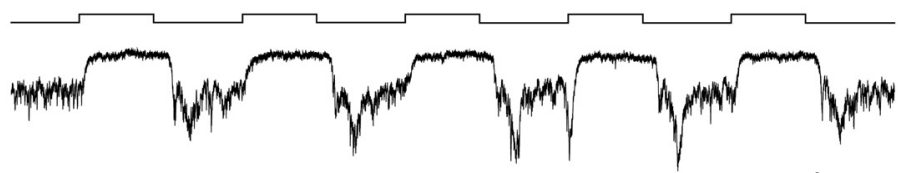

B

Cplx3/4DKO

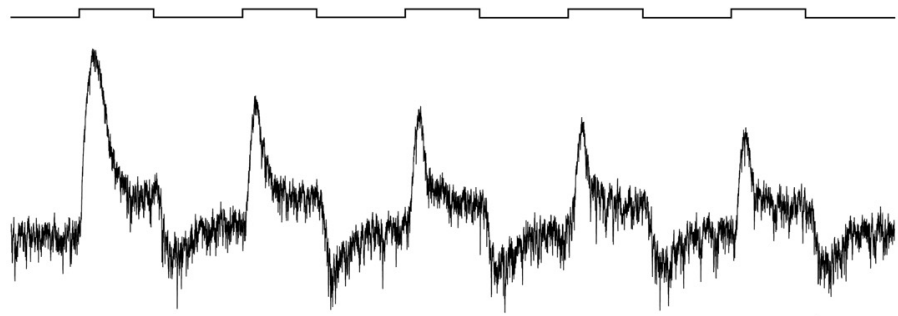

C
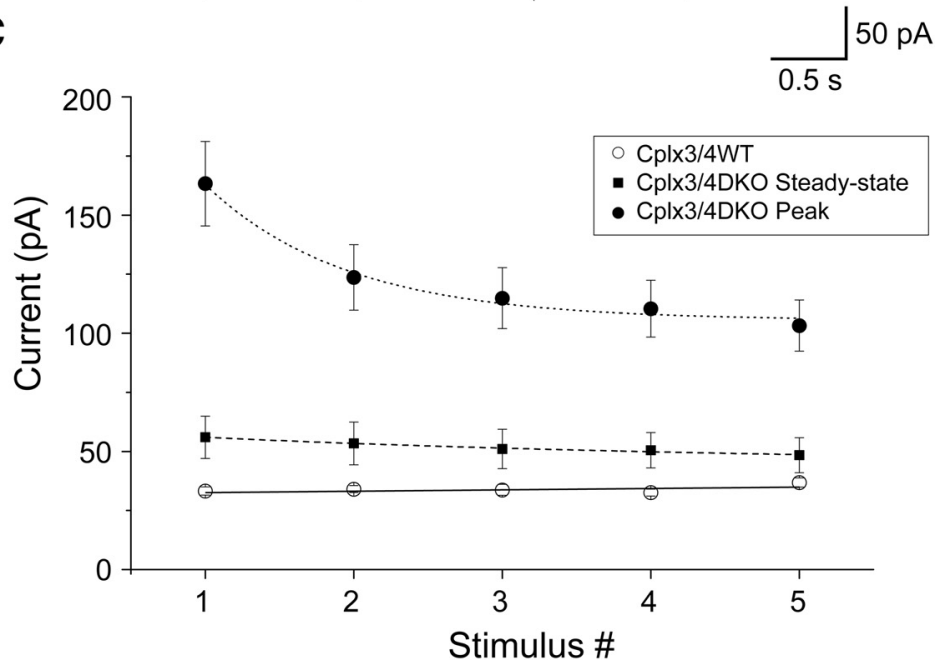

Figure 5. Effect of Cplx3/4 DK0 on repetitive light stimulation. $\boldsymbol{A}$, Response of a relatively dark-adapted horizontal cell from Cplx3/4 WT retina to repetitive full-field stimulation ( $15,000 \mathrm{~lx}, 1 \mathrm{~Hz})$. $\boldsymbol{B}$, Same as $\boldsymbol{A}$ but for $\mathrm{Cplx3/4}$ DKO retina. C, Plot of peak and steady-state current amplitudes for horizontal cells from Cplx3/4 WT and Cplx3/4 DK0 retinas. Peak and steady-state were determined as shown in Figure 4. Data points were fitted with a linear regression line (Cplx3/4 WT) and two monoexponential functions (Cplx3/4 DK0 Peak, Cplx3/4 DK0 steady-state). In horizontal cells from Cplx3/4 WT retina, no correlation was observed between current amplitude and stimulus number (Pearson $r=0.55083 ; R^{2}=0.07122$ ). $R^{2}$ values for the monoexponential fits were 0.97765 and 0.96154 for peak and steady-state, respectively. Fitting a linear regression line to the steady-state data points resulted in a similar correlation coefficient $\left(R^{2}=0.9486\right)$.

stants of the decay of spatially averaged $\mathrm{Ca}^{2+}$ signals remained unaltered (Fig. 2C-E). Relative fluorescence changes in Cplx3/4 WT versus Cplx3/4 DKO photoreceptor terminals were $1.30 \pm$ 0.13 and $1.28 \pm 0.11$, respectively $(p=0.91, t$ test $)$. Decay time constants in Cplx3/4 WT versus Cplx3/4 DKO photoreceptor terminals were $20.54 \pm 1.20 \mathrm{~s}$ and $21.26 \pm 0.83 \mathrm{~s}$, respectively ( $p=0.63, t$ test; $n=14,3$ mice each).

\section{Lack of Cplx3 and Cplx4 affects the HC light response}

Measuring baseline EPSCs is a straightforward but poorly controllable readout of presynaptic random vesicle fusion. To trigger the synapse between cone photoreceptors and $\mathrm{HC}$ bodies with a better-defined stimulus, we used brief light pulses of fixed intensity and variable duration to determine whether the $\mathrm{HC}$ light response was affected by Cplx3/4 deficiency.

Photoreceptors continuously release glutamate in the dark, thereby inducing a constant inward current in postsynaptic horizontal and OFF bipolar cells. In voltage-clamp recordings of
HCs, a corresponding DC offset was thus routinely observed at a holding potential of $-60 \mathrm{mV}$ under relatively dark-adapted conditions. In addition, the inward current appeared noisy due to the ceaseless opening and closing of ionotropic glutamate receptor channels. When glutamate release was reduced by full-field illumination $(15,000 \mathrm{~lx})$, the inward current was blocked, accompanied by a reduction of synaptic noise.

We assessed the responses of relatively dark-adapted Cplx3/4 WT HCs to light stimuli of fixed intensity and duration increasing from $1 \mathrm{~ms}$ to $2 \mathrm{~s}$ (Fig. $3 A$ ). Whereas a $1 \mathrm{~ms}$ stimulus had little effect beyond noise level, longer stimulus durations consistently induced a clear response, characterized by a block of tonic inward current and reduced synaptic noise in the presence of the stimulus. At light offset, a transient inward current was frequently observed.

When the same light stimulus protocol was applied to relatively dark-adapted HCs from Cplx3/4 DKO mice, however, the $\mathrm{HC}$ responses differed in terms of amplitude and kinetics from those of Cplx3/4 WT. A stimulus of $1 \mathrm{~ms}$ already elicited a significantly increased response compared with Cplx3/4 WT mice (Fig. 3B). In general, the amplitude of the tonic inward current, measured as the difference between the apparent baseline in the dark and the peak of the light response, was always larger in Cplx3/4 DKO mice. As a direct consequence of the elevated DC offset, peak light responses rose from $\sim 50.3 \pm 3.9 \mathrm{pA}$ in $\mathrm{Cplx} 3 / 4 \mathrm{WT}$ mice to $168.6 \pm 7.6 \mathrm{pA}$ in Cplx3/4 DKO mice, corresponding to an increase of $335 \%$ (Fig. 4A). The increased HC light response suggests that the lack of Cplx3 and $\mathrm{Cplx} 4$ causes greater $\mathrm{Ca}^{2+}$-dependent release of glutamate from cone photoreceptors in the dark.

At light offset, a transient inward current or OFF component frequently became apparent. In both Cplx3/4 WT and Cplx3/4 DKO mice, the amplitude of the OFF component showed no correlation to the duration of the stimulus and it appeared not to be affected by the absence of Cplx3 and Cplx4 (Fig. 4B). Mean and variance of the normally distributed data points did not differ significantly (mean, $p=0.356$, paired $t$ test; variance, $p=0.245$, Levene test).

In clear contrast to $\mathrm{Cplx} 3 / 4 \mathrm{WT}$, the light response measured in Cplx3/4 DKO mice showed a transient current trajectory, which became especially pronounced with light stimuli of $100 \mathrm{~ms}$ or longer (Fig. 3B). Therefore, the current returned to a steadystate value, although the stimulus was still present. The steadystate was not identical to the baseline level in the dark. The transient nature of the light responses was determined as the ratio of amplitudes obtained before and at the end of the light response. In accordance with their plateau-like appearance, the 
A

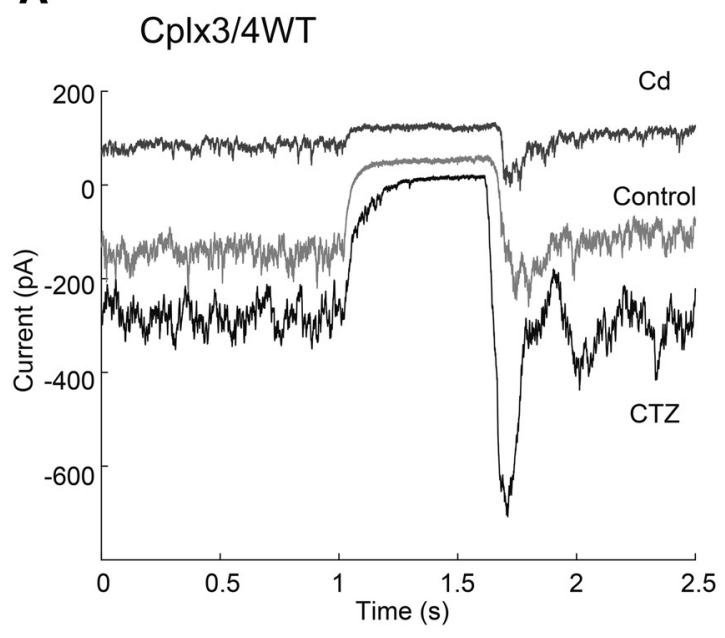

C

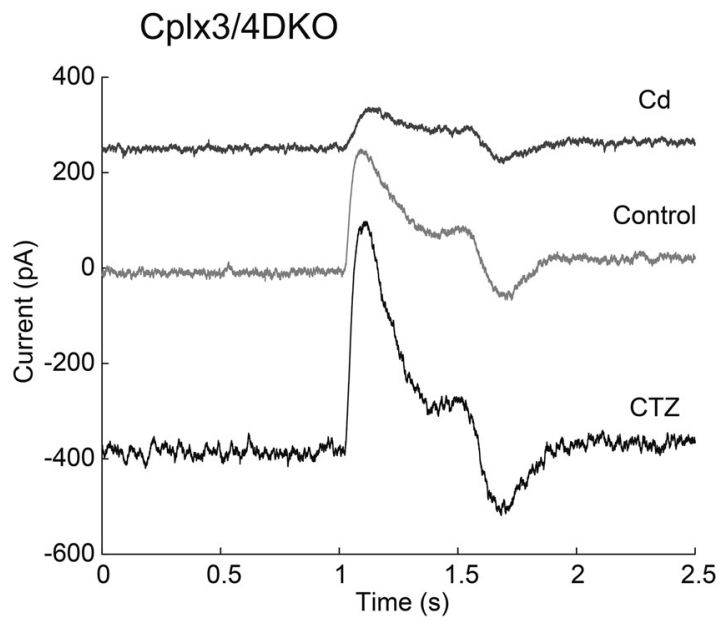

B
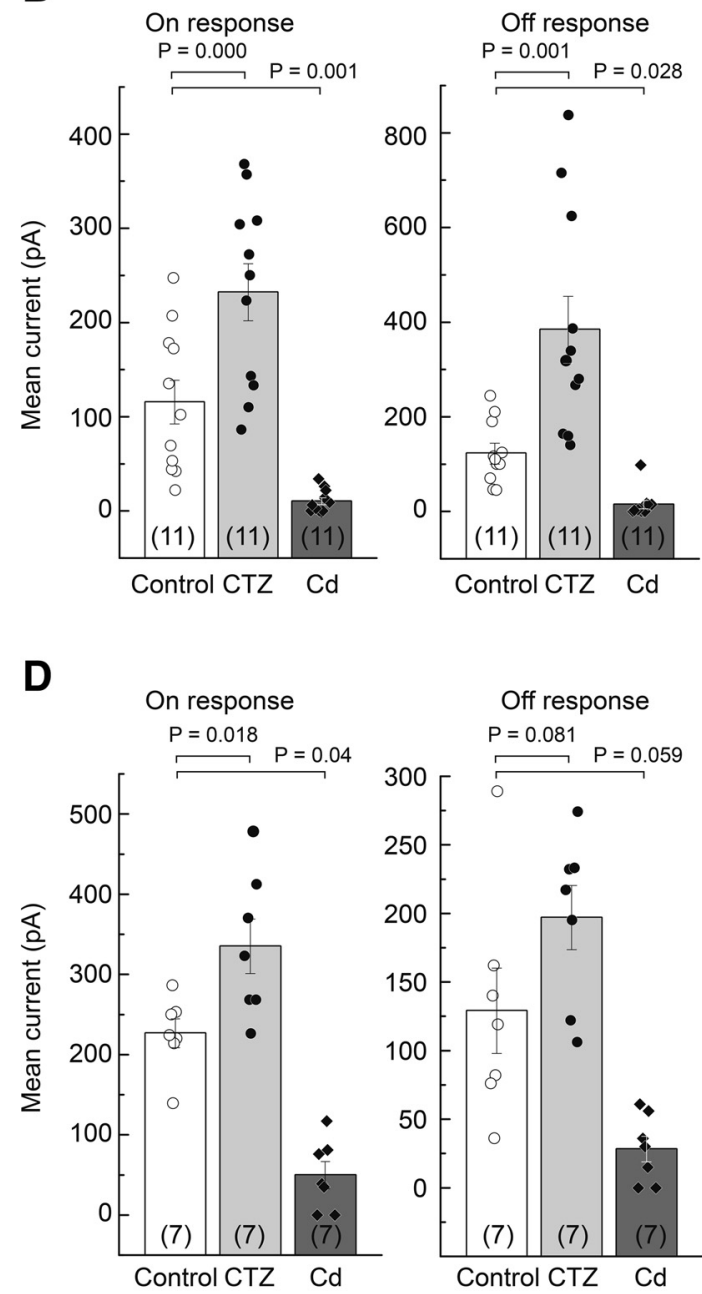

Figure 6. Effect of cyclothiazide and cadmium on light response amplitude in Cplx3/4 WT and Cplx3/4 DK0 mouse retinas. $A$, Response of a relatively dark-adapted horizontal cell from Cplx3/4 WT retina to full-field stimulation $(15,000 \mathrm{~lx}, 500 \mathrm{~ms})$ under control conditions and in the presence of $100 \mu \mathrm{M}$ CTZ or $100 \mu \mathrm{m} \mathrm{Cd}^{2+}$. B, Combined bar graph and scatter plot showing the effect of CTZ and $\mathrm{Cd}^{2+}$ on the $\mathrm{ON}$ and OFF response amplitudes. Values differ significantly as indicated by the $p$-values (paired $t$ test, Bonferroni correction for multiple comparisons). $C$, Response of a relatively dark-adapted horizontal cell from Cplx3/4DKO retina to full-field stimulation under the same conditions as shown in A.D, Summary of CTZ and Cd ${ }^{2+}$ effects on the $0 \mathrm{~N}$ and 0 FF response. Values differ significantly only for the $\mathrm{ON}$ response (paired $t$ test, Bonferroni correction).

ratio of Cplx3/4 WT light responses was close to $1(0.994 \pm$ $0.014)$. For Cplx3/4 DKO mice, however, the ratio was reduced to $0.285 \pm 0.014$, reflecting the decay of the current trace to $<1 / 3$ of peak amplitudes (Fig. 4C).

Light responses from Cplx3/4 WT and Cplx3/4 DKO mice also differed significantly in the amount of synaptic noise in relative darkness and during illumination. Because of the transient nature of the Cplx3/4 DKO light response, this difference was most pronounced with light stimuli lasting $1 \mathrm{~s}$ or longer (Fig. 3). Current segments of $500 \mathrm{~ms}$ under dark and light conditions were chosen to determine the variance of postsynaptic events as a measure of synaptic noise.

In Cplx3/4 WT HCs, the variance was significantly larger in relative darkness compared with light $\left(p=5.12 \times 10^{-4}\right.$, paired $t$ test; Fig. $4 D)$. Mean values were $72.1 \pm 10.0 \mathrm{pA}^{2}$ for darkness and $4.7 \pm 0.6 \mathrm{pA}^{2}(n=7)$ for light. However, with mean values of $109.9 \pm 17.6 \mathrm{pA}^{2}$ and $100.8 \pm 17.4 \mathrm{pA}^{2}(n=10)$ for dark and light, respectively, the variance of postsynaptic currents measured in Cplx3/4 DKO HCs was not significantly different ( $p=$ 0.06 , paired $t$ test; Fig. $4 E$ ). The transient nature of the current response and the elevated level of synaptic noise indicate that, even under prolonged illumination, neurotransmitter was continuously released in the absence of Cplx3 and Cplx4.

Finally, we investigated the effect of $\mathrm{Cplx} 3 / 4 \mathrm{DKO}$ on repeated light stimulation. Repetitive pulses of full-field illumination $(15,000 \mathrm{~lx})$ were presented at a frequency of $1 \mathrm{~Hz}$ to relatively dark-adapted HCs (Fig. 5). Peak response amplitudes of Cplx3/4 WT HCs did not change during the train of stimuli (Fig. $5 A$ ). Therefore, plotting current amplitudes versus stimulus number produced a straight line (Fig. $5 C$ ). In contrast, peak amplitudes measured in HCs from Cplx3/4 DKO mice clearly showed a nonlinear decline with progressing stimulation (Fig. $5 B, C)$. The steady-state current measured at the end of each light stimulus also declined exponentially, but showed a much slower time course of decay (Fig. $5 C$ ). These results indicate that the absence of Cplx3 and Cplx4 gradually attenuates the capability of the cone photoreceptor synapse to process repetitive light stimulation.

To rule out a potential postsynaptic effect of Cplx3/4 deficiency, we investigated the effect of cyclothiazide (CTZ) on the 

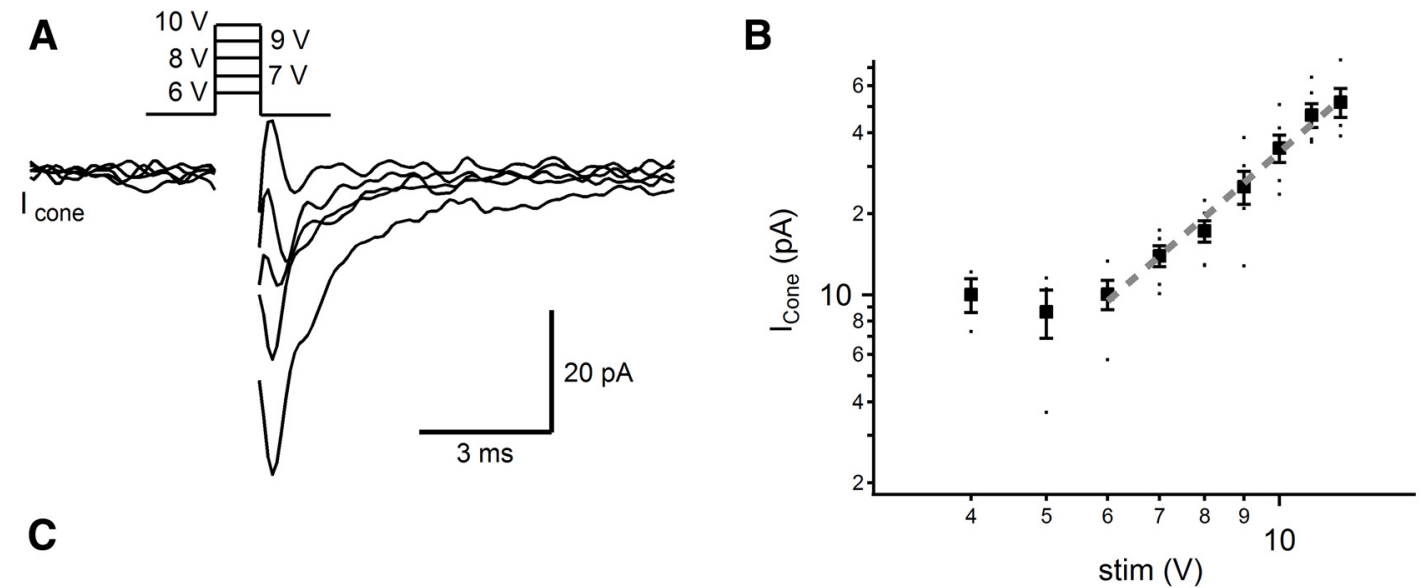

C
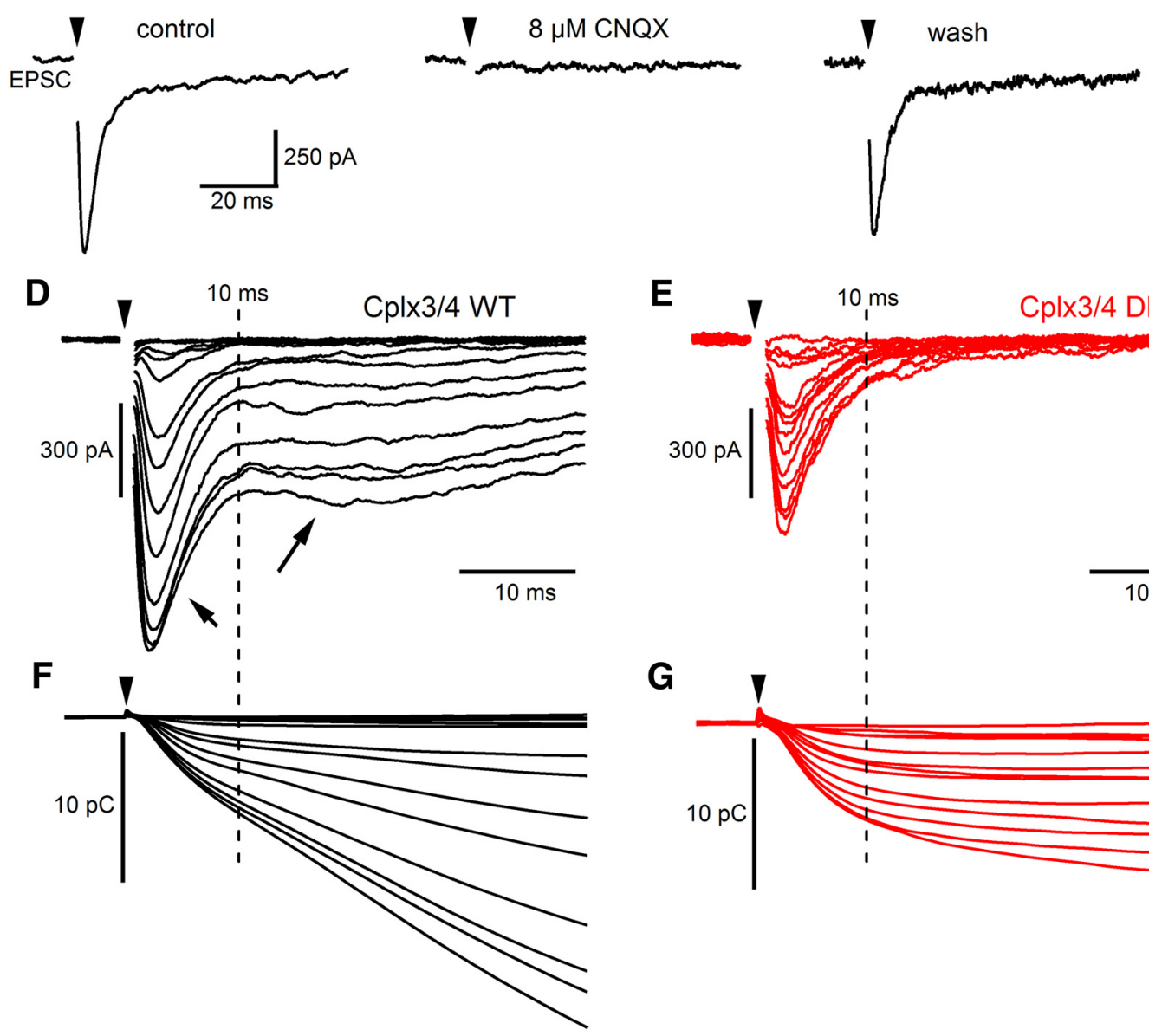

E
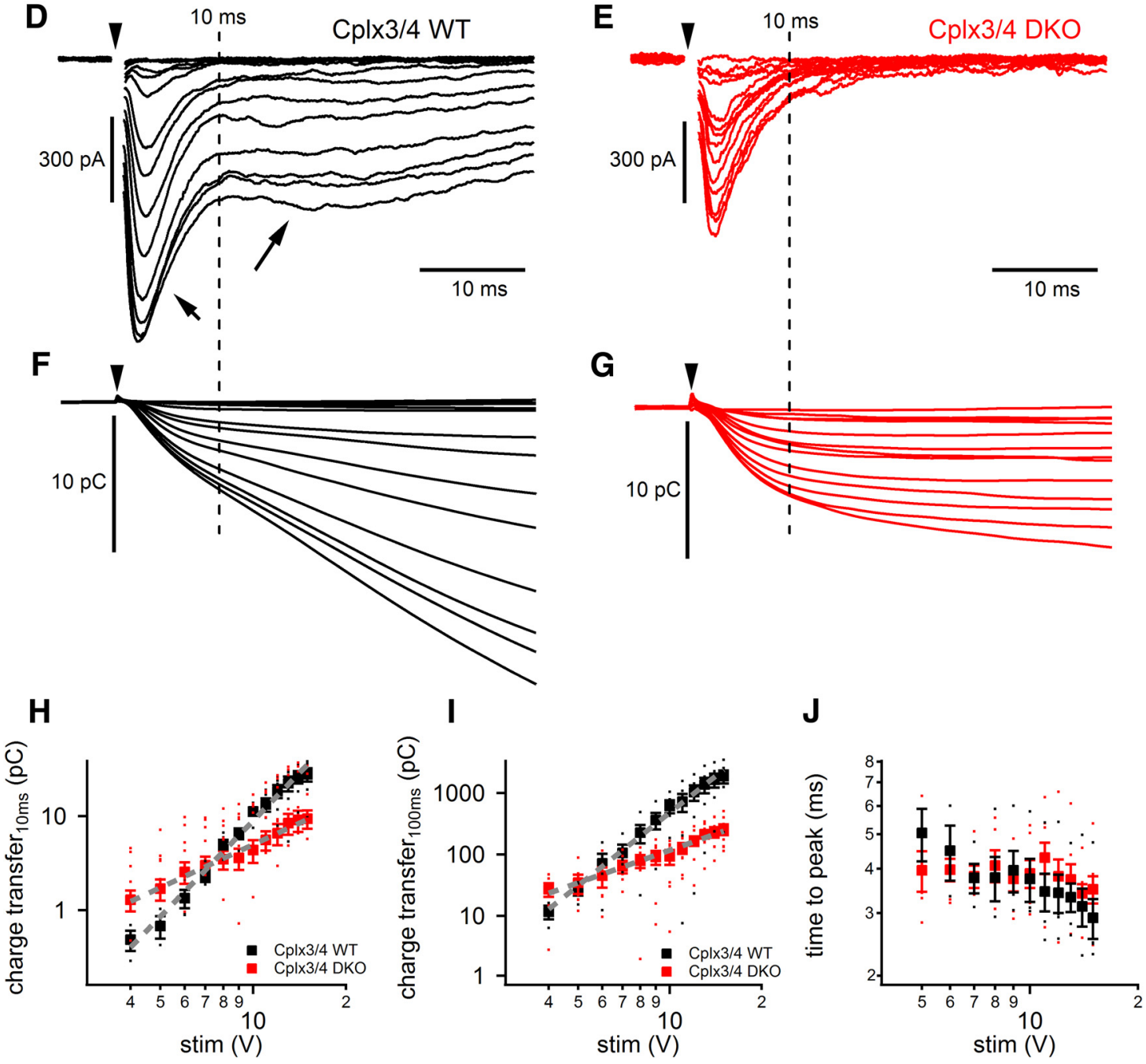

Figure 7. Electrical stimulation reveals altered synaptic release in photoreceptor of ( $\mathrm{pl} 33 / 4 \mathrm{DK} 0$ mice. $A$, Inward currents elicited by electrical stimulation ( $6-10 \mathrm{~V}, 1 \mathrm{~ms}$ duration) were measured in cone photoreceptors. Responses were measured in vertical slices of Rac3-EGFP mice, in which the EGFP-labeled cone photoreceptor terminals could be easily identified. For clarity, stimulation artifacts were removed from the current traces. $\boldsymbol{B}$, Plot of peak cone inward currents versus stimulus amplitude (4-10 V, $1 \mathrm{~ms}$ duration) reveals a linear (Figure legend continues.) 
HC light response in Cplx3/4 WT and Cplx3/4 DKO animals. CTZ blocks fast desensitization of AMPA and kainate receptors, thereby enhancing glutamatergic synaptic transmission (Yamada and Tang, 1993). In the presence of $100 \mu \mathrm{M} C T Z$, the constant inward current in darkness was increased in Cplx $3 / 4$ WT animals, leading to an enhanced response at light offset (Fig. 6A,B). Light-induced inhibition of inward current increased from $116 \pm$ $23 \mathrm{pA}$ under control conditions to a mean value of $232 \pm 30 \mathrm{pA}$ in the presence of CTZ (Fig. 6B, left). The response at current offset also increased from $123 \pm 18$ to $384 \pm 71 \mathrm{pA}$ in the presence of CTZ (Fig. 6B, right). In Cplx3/4 DKO mice, CTZ also induced a significant shift of tonic inward currents (Fig. 6C). As a consequence, the $\mathrm{ON}$ response increased from $226 \pm 17 \mathrm{pA}$ under control conditions to $335 \pm 34 \mathrm{pA}$ after application of CTZ (Fig. $6 D$, left). The OFF response was not significantly affected, with a control value of $129 \pm 31$ and $197 \pm 23 \mathrm{pA}$ in the presence of CTZ (Fig. $6 D$, right). CTZ did not change the kinetics of the light responses in Cplx3/4 WT and Cplx3/4 DKO animals. The 10$90 \%$ rise time, $10-90 \%$ decay time, and exponential decay of the current trace during illumination in Cplx $3 / 4$ DKO animals were unaltered by CTZ (data not shown).

In addition, we measured the effect of blocking presynaptic $\mathrm{Ca}^{2+}$ channels with $100 \mu \mathrm{M}$ cadmium $\left(\mathrm{Cd}^{2+}\right)$. Due to block of calcium-dependent glutamate release, the tonic current offset was inhibited in both Cplx3/4 WT and Cplx3/4 DKO animals (Fig. $6 \mathrm{~A}, \mathrm{C}$ ). A residual small-amplitude light response was observed in seven of 11 cells in Cplx $3 / 4$ WT mice and in five of seven cells in Cplx3/4 DKO animals. The incomplete block by $\mathrm{Cd}^{2+}$ observed in a substantial number of cells was most likely due to obstruction of diffusion within the tissue, so the effective concentration of $\mathrm{Cd}^{2+}$ at some synaptic release sites was too low to fully block $\mathrm{Ca}^{2+}$ channels in cone photoreceptor terminals. In these cells, even prolonged application $(>3 \mathrm{~min})$ of $\mathrm{Cd}^{2+}$ led to a steady-state in which the residual light response could not be reduced any further.

Because both light and $\mathrm{Cd}^{2+}$ eventually lead to reduced transmitter release, we compared the effects of both treatments on membrane currents on HCs of Cplx3/4 WT and Cplx3/4 DKO mice.

\footnotetext{
$\leftarrow$

(Figure legend continued.) relationship between 6 and $10 \mathrm{~V}$ (slope: $2.49 \pm 0.12 \mathrm{pA} / \mathrm{V} ; r^{2}=$ 0.9884 ; dashed gray line). C, Application of $8 \mu \mathrm{m}$ CNQX blocks the evoked postsynaptic current measured in a Cplx3/4 WT horizontal cell. Arrowheads label the timing of a single electrical stimulus (10 V, $1 \mathrm{~ms}$ duration). Holding potential: $-60 \mathrm{mV}$. D, Membrane currents recorded from a horizontal cell from (plx3/4 WT retina voltage-clamped at $-60 \mathrm{mV}$. Photoreceptors were depolarized by a $1 \mathrm{~ms}$ electrical stimulus (arrowhead) with variable amplitudes ranging from 1 to $15 \mathrm{~V}$. Increased stimulation strength evoked larger EPSCs displaying a fast and a slow component (short and long arrows, respectively). The dashed line represents an arbitrary separation of the two components $10 \mathrm{~ms}$ after onset of the stimulus. $\boldsymbol{E}$, Membrane currents recorded from a horizontal cell from Cplx3/4 DKO retina. Experimental conditions were as in $\boldsymbol{D}$. $\boldsymbol{F}$, $\boldsymbol{G}$, Charge transfer during evoked EPSCs from the same horizontal cells shown in $\boldsymbol{D}$ and $\boldsymbol{E}$, respectively. The dashed line represents $10 \mathrm{~ms}$ after stimulus onset. $\boldsymbol{H}, \boldsymbol{I}$, Charge transfer during evoked EPSCs was plotted against stimulus amplitude. Charge transfer was measured during the first $10 \mathrm{~ms}$ after the stimulus onset $(\boldsymbol{H})$ and from 10 to $100 \mathrm{~ms}(\boldsymbol{I})$. Data points (5-15 V) were fitted with a linear fitting routine in double-logarithmic space (gray, dashed line) for the first 10 $\mathrm{ms}$, yielding slope values of $3.39 \pm 0.12 \mathrm{pC} / \mathrm{V}\left(r^{2}=0.9885\right)$ and $1.82 \pm 0.08 \mathrm{pC} / \mathrm{V}\left(r^{2}=\right.$ 0.9783 for Cplx3/4 WT and Cplx3/4 DK0 retinas, respectively $(\boldsymbol{H})$. Between 10 and $100 \mathrm{~ms}$, corresponding slope values were $3.95 \pm 0.10 \mathrm{pC} / \mathrm{V}\left(r^{2}=0.9949\right)$ and $1.76 \pm 0.08 \mathrm{pC} / \mathrm{V}\left(r^{2}=\right.$ 0.9771 ) for (plx3/4 WT and (plx3/4 DK0 retinas, respectively (I). Charge transfer values were significantly different for EPSCs evoked by electrical stimuli ranging from 9 to $15 \mathrm{~V}$. Unpaired $t$ test: $p=0.04(9 \mathrm{~V}), 0.0014(10 \mathrm{~V}), 0.0116(11 \mathrm{~V}), 0.0055(12 \mathrm{~V}), 0.0055(13 \mathrm{~V}), 0.0041(14 \mathrm{~V})$, and 0.0031 ( $15 \mathrm{~V} ;(\mathrm{pl} \times 3 / 4 \mathrm{WT}: n=6$; (plx3/4 DK0: $n=7)$. J, Plot of time-to-peak values of EPSC from the onset of the electrical stimulation at $15 \mathrm{~V}$ stimulation voltage. The small dots in $\boldsymbol{H}-\boldsymbol{J}$ represent individual data points.
}

Whereas no change was observed in current reduction in Cplx $3 / 4$ WT ( $p=0.281$, paired $t$ test), the inhibitory effect of $\mathrm{Cd}^{2+}$ was significant in Cplx3/4 DKO animals ( $p=0.00891$, paired $t$ test), suggesting that even strong illumination did not entirely block glutamate release from cone photoreceptors in the absence of $\mathrm{Cplx} 3$ and Cplx4.

Together, these results indicate that the altered light response of Cplx3/4 DKO mice was not caused by changes on the level of presynaptic $\mathrm{Ca}^{2+}$ channels (see also Fig. 2) or postsynaptic glutamate receptors.

\section{Lack of Cplx3 and Cplx4 affects evoked synaptic vesicle release}

To access ribbon synaptic release from photoreceptors, we electrically stimulated photoreceptors with a bipolar electrode while simultaneously recording $\mathrm{HC}$ membrane currents in a horizontal slice preparation of Cplx3/4 WT and Cplx3/4 DKO mice. In the retina, electrical stimulation as a trigger for synaptic release has been described for rod photoreceptors (Hasegawa et al., 2006), bipolar cells (Higgs and Lukasiewicz, 1999), and amacrine cells (Moore-Dotson et al., 2015).

To assess the effect of extracellular electrical stimulation on photoreceptors, we first measured membrane currents of cone photoreceptors in a vertical slice preparation while applying voltage pulses ranging from 6 to $10 \mathrm{~V}$ (Fig. 7A). In Rac3-EGFP mice, cone photoreceptors could be easily visualized due to their expression of EGFP (Fuchs et al., 2014). Whole-cell inward currents showed a close relation to stimulus strength (Fig. 7B). In addition, electrical stimulation evoked an EPSC in HCs (Fig. 7C, left) that could be blocked by extracellular application of $8 \mu \mathrm{M} C N Q X$ (Fig. $7 C$, middle), a competitive AMPA/kainate receptor antagonist. The effect was fully reversible after 3 min (Fig. $7 C$, right). These findings clearly indicate that responses measured in HCs were caused by evoked synaptic release of glutamate due to electrical stimulation of presynaptic cone photoreceptors.

To investigate a possible effect of Cplx $3 / 4$ on evoked synaptic vesicle release at the cone photoreceptor ribbon synapse, we measured HC EPSCs in Cplx3/4 WT and Cplx3/4 DKO mice. Amplitudes of single electrical pulses ( $1 \mathrm{~ms}$ duration) ranged between 1 and $15 \mathrm{~V}$. In Cplx $3 / 4$ WT mice, the size of individual EPSCs increased with stimulus strength (Fig. 7D). Evoked EPSCs displayed a characteristic current trajectory with an early transient component (Fig. $7 D$, short arrow) and a late sustained component (Fig. $7 D$, long arrow). Neither of the components was affected by the gap junction blocker meclofenamic acid $(n=3$, data not shown), indicating that coupling between rod and cone photoreceptors, or between neighboring HCs, did not shape the postsynaptic response.

EPSC amplitudes recorded from Cplx $3 / 4 \mathrm{WT}$ and Cplx $3 / 4$ DKO mouse HCs were related to stimulus voltage, but significantly smaller peak amplitudes were observed in Cplx $3 / 4$ DKO animals at all voltages tested (Fig. $7 E$ ). At $15 \mathrm{~V}$ stimulus strength, mean amplitudes were $450 \pm 57 \mathrm{pA}(n=6)$ in Cplx $3 / 4$ DKO mice versus $931 \pm 122 \mathrm{pA}$ in Cplx3/4 WT mice $(n=7, p=0.008$, unpaired $t$ test). In addition, EPSCs of Cplx $3 / 4$ DKO mice almost entirely lacked the sustained component of the postsynaptic response (Fig. 7E)

To evaluate synaptic release from photoreceptors, we measured the cumulative charge transfer by integrating EPSCs evoked by electrical stimulation (Fig. $7 F, G$ ). Figure 7, $H$ and $I$, shows the increase in charge transfer representing the synaptic vesicles released during the first $10 \mathrm{~ms}$ and from 10 to $100 \mathrm{~ms}$, respectively, as a function of stimulation strength. Data points 

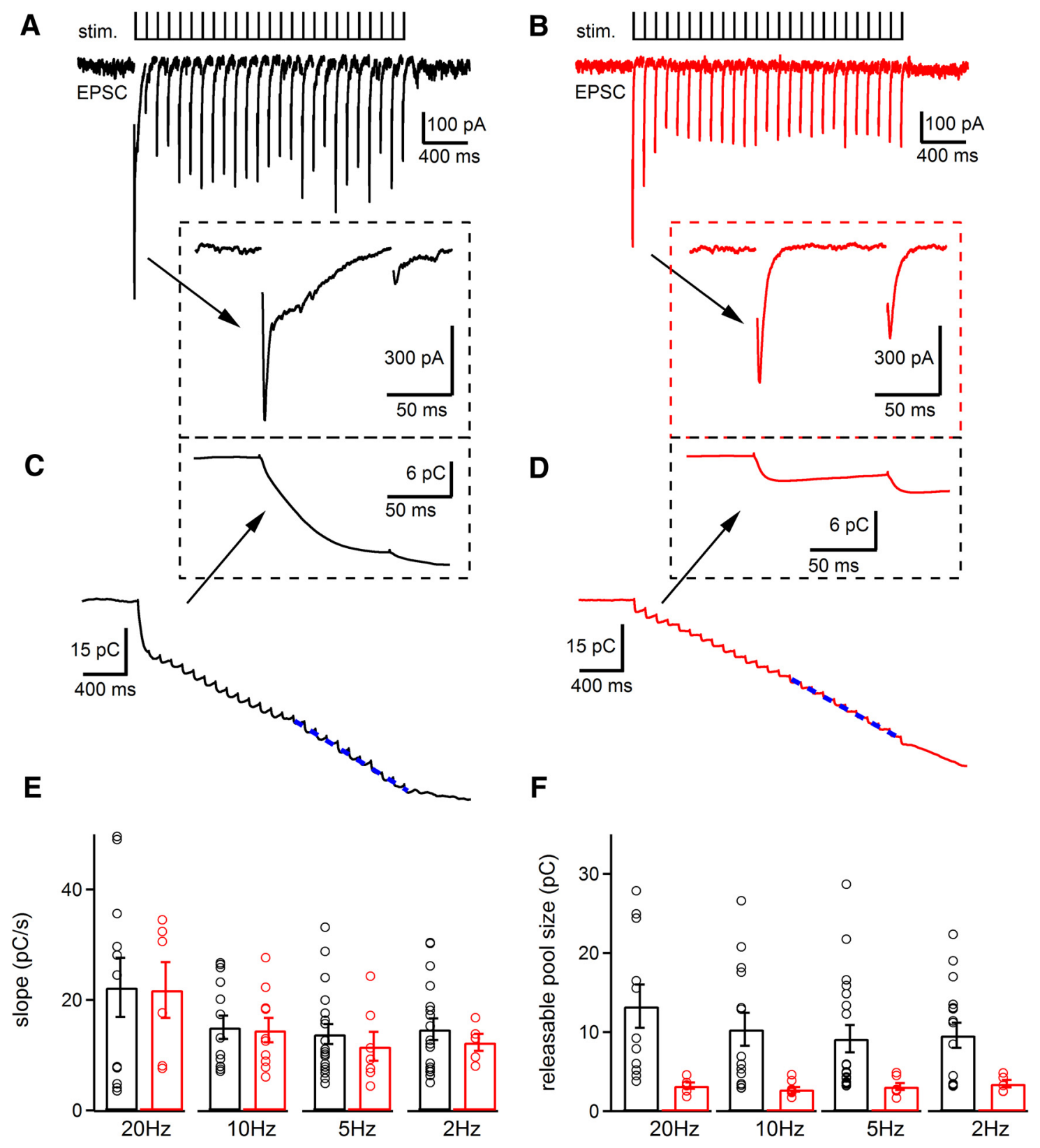

Figure 8. EPSCs evoked by trains of electrical stimulation reveal similar synaptic vesicle replenishment rates but altered releasable pool size in Cplx3/4 WT and Cplx3/4 DK0 mouse photoreceptors. $A$, EPSCs were evoked by a train of electrical stimulation ( $1 \mathrm{~ms}, 13 \mathrm{~V}, 10 \mathrm{~Hz}, 25$ stimuli) in a horizontal cell from Cplx $3 / 4 \mathrm{WT}$ retina. Inset shows the responses to the first two stimuli at higher temporal resolution. Stimulation artifacts were removed for clarity. B, EPSCs recorded from a horizontal cell from Cplx3/4 DKO retina with the same stimulus train. Inset shows the responses to the first two stimuli at higher temporal resolution. C, Charge transfer during a train of EPSCs recorded from a horizontal cell from Cplx $3 / 4$ WT retina shown in $A$. Inset depicts the charge transfer for the first two stimuli at higher temporal resolution. $\boldsymbol{D}$, Charge transfer during a train of EPSCs recorded from a horizontal cell from Cplx3/4 DKO retina in $\boldsymbol{B}$. Inset depicts the charge transfer for the first two stimuli at higher temporal resolution. The dotted blue lines in $\boldsymbol{C}$ and $\boldsymbol{D}$ represent a linear fit to the charge transfer measured during the last 10 stimuli. $\boldsymbol{E}$, Slope values revealing replenishment rates were obtained by fitting linear regression lines to the cumulative charge transfer as shown in $\boldsymbol{C}$ and $\boldsymbol{D}$. Slope values for horizontal cells from Cplx3/4 WT and Cplx3/4 DKO retinas were not significantly different for all stimulation frequencies tested ( $2 \mathrm{~Hz}: p=0.53, n=11$ and 6; $5 \mathrm{~Hz}: p=0.39, n=19$ and 6; $10 \mathrm{~Hz}: p=0.87, n=14$ and 10;20 Hz: $p=0.95, n=11$ and 6, unpaired $t$ test). $\boldsymbol{F}$, Comparison of releasable pool size measured with electrical stimulation at frequencies of 2, 5, 10, and $20 \mathrm{~Hz}$. Values showed significant differences between (plx3/4 WT and Cplx3/4 DKO photoreceptors ( $2 \mathrm{~Hz}: p=0.05 ; 5 \mathrm{~Hz}: p=0.045 ; 10 \mathrm{~Hz}: p=0.006 ; 20 \mathrm{~Hz}: p=0.017$, unpaired $t$ test). Holding potential in all experiments was $-60 \mathrm{mV}$.

were fitted with a log-log fitting routine, yielding slope values of $3.39 \pm 0.12 \mathrm{pC}$ for Cplx $3 / 4$ WT and $1.53 \pm 0.06 \mathrm{pC}$ for Cplx3/4 DKO mice during the first $10 \mathrm{~ms} \mathrm{(} p=0.382$, unpaired $t$ test; Fig. $7 H)$ and $3.95 \pm 0.11 \mathrm{pC}$ for $\mathrm{Cplx} 3 / 4 \mathrm{WT}$ and $1.76 \pm 0.08 \mathrm{pC}$ for Cplx3/4 DKO mice from 10 to $100 \mathrm{~ms}$ ( $p=0.036$, unpaired $t$ test; Fig. 7I).

Charge transfer values of the first $10 \mathrm{~ms}$ at lower stimulation strength $(<6 \mathrm{~V})$ in case of Cplx3/4 DKO mice had a tendency to be higher than in Cplx3/4 WT mice (Fig. 7H). These results agree with the higher frequency and amplitude of $\mathrm{Ca}^{2+}$-dependent tonic vesicle release measured under relatively dark-adapted conditions (Fig. 1). Time-to-peak values of Cplx3/4 WT and Cplx3/4 DKO mice were not significantly different at $15 \mathrm{~V}(p=0.24$, unpaired $t$ test; Fig. 7J). In summary, Cplx3/4 increased peak amplitude and charge transfer of evoked postsynaptic currents, indicating higher synaptic vesicle release rates. 
Table 1. Average and variance of ESPC ${ }_{11 \text { th-25th }}$

\begin{tabular}{|c|c|c|c|}
\hline \multicolumn{4}{|c|}{ Average of EPSC ${ }_{11 \text { th-25th }} / \mathrm{EPSC}_{1 \mathrm{st}}$} \\
\hline Frequency $(\mathrm{Hz})$ & Cplx3/4 WT & Cplx3/4 DK0 & $p$-value \\
\hline 2 & $0.93 \pm 0.06$ & $0.80 \pm 0.04$ & 0.16 \\
\hline 5 & $0.71 \pm 0.07$ & $0.73 \pm 0.06$ & 0.88 \\
\hline 10 & $0.48 \pm 0.05$ & $0.52 \pm 0.05$ & 0.50 \\
\hline 20 & $0.34 \pm 0.03$ & $0.38 \pm 0.05$ & 0.52 \\
\hline \multicolumn{4}{|c|}{ Variance of EPSC ${ }_{11 \text { th-25th }}$} \\
\hline Frequency $(\mathrm{Hz})$ & Cplx3/4 WT $\left(\mathrm{pA}^{2}\right)$ & Cplx3/4 DKO $\left(\mathrm{pA}^{2}\right)$ & $p$-value \\
\hline 2 & $987.3 \pm 204.5$ & $1082.2 \pm 234.6$ & 0.76 \\
\hline 5 & $1365.9 \pm 263.0$ & $1275.2 \pm 286.5$ & 0.84 \\
\hline 10 & $1356.1 \pm 325.8$ & $487.4 \pm 60.5$ & 0.03 \\
\hline 20 & $1521.7 \pm 444.5$ & $433.4 \pm 88.1$ & 0.05 \\
\hline
\end{tabular}

$p$-values were obtained with unpaired $t$ test.

\section{Lack of Cplx3 and Cplx4 does not affect synaptic vesicle} replenishment rates but decreases releasable vesicle pool size To measure rates of vesicle replenishment at the photoreceptor ribbon synapses, we applied trains of electrical stimulation to photoreceptors while recording EPSCs from Cplx3/4 WT and Cplx3/4 DKO HCs. The stimulation protocol has been shown for the calyx synapse (Schneggenburger et al., 1999) and the cone photoreceptor ribbon synapse (Babai et al., 2010) to empty the releasable vesicle pool and thereby attain a steady-state level, where the rate of replenishment limits the rate of release.

In Figure $8 A$, a train of 25 stimuli ( $12 \mathrm{~V}$ each) was applied at a frequency of $10 \mathrm{~Hz}$ to a retinal slice from a Cplx $3 / 4 \mathrm{WT}$ mouse. EPSC amplitudes decreased after the first EPSC (Fig. 8A, inset) and reached smaller values with consecutive stimulation. The same stimulation paradigm $(12 \mathrm{~V}, 10 \mathrm{~Hz})$ elicited a similar response in a Cplx3/4 DKO mouse (Fig. $8 B$ ), which was quantified by calculating the amplitude ratio of the first and the arithmetic mean of the last 15 EPSCs (Table 1). We also quantified the variance of the last 15 EPSC amplitudes and found it significantly different for higher frequencies in the Cplx3/4 DKO mice (Table 1), suggesting decreased release probability in Cplx3/4 DKO synapses.

To reveal the replenishment rate, we measured the cumulative charge transfer by integrating the EPSCs obtained from HCs from Cplx3/4 WT and Cplx3/4 DKO mice (Fig. 8C,D). The rate of replenishment was calculated from the slope of a straight line fit to the cumulative charge transfer during the last 10 stimuli of the train when replenishment balances release.

Using this procedure, replenishment rates were measured at different stimulation frequencies $(2,5,10$, and $20 \mathrm{~Hz})$. At a given frequency, replenishment rates were not significantly different when comparing Cplx3/4 WT and Cplx3/4 DKO photoreceptors (Fig. $8 E$ ). We also compared the releasable vesicle pool size by determining the Y-intercept of the straight line fit (Fig. $8 C, D$, blue dashed line) to the cumulative charge transfer and found the values to be significantly smaller for Cplx3/4 DKO mice at all applied stimulation frequencies (Fig. $8 F$ ).

\section{Intact molecular anatomy of photoreceptor ribbon synapses in Cplx3/4 DKO mice}

Because of the aberrant functional phenotype of Cplx3/4 DKO cone photoreceptor ribbon synapses, we next addressed their molecular architecture with immunocytochemistry and light microscopy. In triple-labeling experiments, we analyzed the arrangement of key presynaptic and postsynaptic proteins at cone photoreceptor terminals in Cplx3/4 WT and Cplx3/4 DKO mice. We stained vertical retinal sections for Piccolo/Piccolino (Dick et al., 2001; Regus-Leidig et al., 2013), which marks the site of the ribbon); the presynaptic L-type $\mathrm{Ca}^{2+}$ channel subunit $\alpha 1 \mathrm{f}$ (tom Dieck et al., 2005; Specht et al., 2009), which marks the active zone; and the postsynaptic AMPA glutamate receptor subunit 2 (GluA2), which is present on HC processes and dendrites of OFF cone bipolar cells (Hack et al., 1999, 2001). In a second set of triple-labeling experiments, we stained vertical retinal sections for GluA2; Calbindin (Reim et al., 2009), which marks HC processes; and PNA (Reim et al., 2009), which marks the site of the cone photoreceptor terminal, and used a combination of confocal and STED microscopy. The comparison of the stainings between Cplx3/4 WT and Cplx3/4 DKO mice did not reveal obvious differences in the arrangement of presynaptic $\mathrm{Ca}^{2+}$ channels or of postsynaptic AMPA glutamate receptors and HC processes at the cone photoreceptor terminals (Fig. 9). The results imply that the molecular anatomy of the photoreceptor ribbon synapse, as assessed by the distribution of a selected set of presynaptic and postsynaptic proteins, is essentially intact in Cplx3/4 DKO mice.

\section{Lack of Cplx3 and Cplx4 affects the number of synaptic vesicles at the ribbon base}

The electrophysiological results obtained in the Cplx3/4 DKO mice indicate altered photoreceptor synaptic release properties, with increased tonic activity and light responses of postsynaptic HCs (Figs. 1, 3, 4). Therefore, we examined with quantitative electron microscopy in single ultrathin sections the number and distribution of synaptic vesicles associated with the ribbons in dark- and light-adapted cone and rod photoreceptors of Cplx3/4 WT and Cplx3/4 DKO mice. Importantly, because we have previously shown that a certain percentage of Cplx3/4 DKO photoreceptors contain spherical free-floating ribbons (Reim et al., 2009), we chose for the analysis of ribbon-associated vesicles only photoreceptor ribbon synaptic complexes with a rod-shaped presynaptic ribbon and with both the arciform density and the triadic arrangement of the invaginating postsynaptic elements visible in the section plane.

Mice were dark or light adapted for $3 \mathrm{~h}$ and the vesicle occupancy along the entire height of the ribbon and within $100 \mathrm{~nm}$ of the ribbon base directly adjacent to the arciform density was determined in single ultrathin sections. The number of synaptic vesicles associated within $100 \mathrm{~nm}$ of the ribbon base is given as the percentage of the total vesicle number on the ribbon (100\%) in a given section. Cplx3/4 WT mice showed a clear reduction in the number of synaptic vesicles at the ribbon base after light adaptation (Fig. $10 A-C$ ). For cone photoreceptor ribbons, the average percentage was $40.6 \%$ after dark adaptation versus $21.5 \%$ after light adaptation. For rod photoreceptor ribbons, the average percentage was $39.9 \%$ and $17.8 \%$ after dark and light adaptation, respectively (Fig. 10A-C). This was strikingly different from Cplx3/4 DKO cone and rod photoreceptor ribbons, which did not show significant differences in the number of synaptic vesicles at the ribbon base for dark- and light-adapted conditions (Fig. 10D-F). For cone photoreceptor ribbons, the average percentage was $43.1 \%$ after dark adaptation versus $43.6 \%$ after light adaptation. For rod photoreceptor ribbons, the average percentages were $37.3 \%$ and $36.5 \%$ after dark and light adaptation, respectively (Fig. 10D-F). Importantly, the average height of the analyzed ribbons differed only very little between the two genotypes and adaptation conditions. Mean ribbon height of darkadapted cone photoreceptors ranged from $153 \mathrm{~nm}$ (Cplx3/4 WT) to $161 \mathrm{~nm}(\mathrm{Cplx} 3 / 4 \mathrm{DKO})$, of light-adapted cone photoreceptors from $163 \mathrm{~nm}$ (Cplx3/4 WT) to $166 \mathrm{~nm}$ (Cplx3/4 DKO), of dark- 

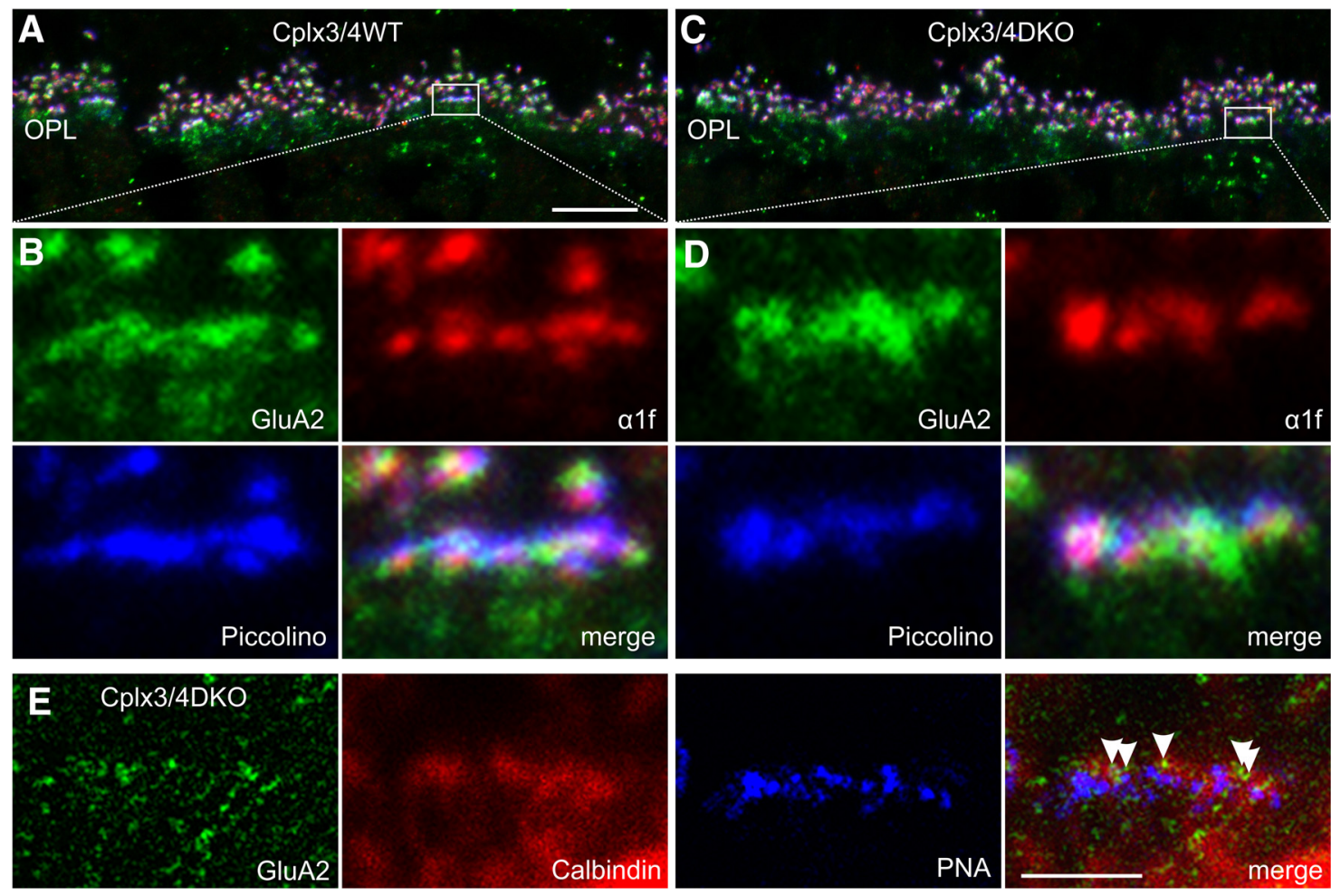

Figure 9. Molecular anatomy of cone photoreceptor ribbon synaptic sites in (plx3/4 WT and Cplx3/4 DK0 mouse retinas. $A, C$, Confocal laser scanning image of the outer plexiform layer (OPL) of Cplx3/4WT ( $A$ ) and (plx3/4 DKO (C) retinas triple labeled with antibodies against GluA2 (green), L-type $\mathrm{Ca}^{2+}$ channel subunit $\alpha 1 \mathrm{f}(\mathrm{red})$, and Piccolino (blue). $\boldsymbol{B}, \boldsymbol{D}$, High-power views of the boxed areas in $\boldsymbol{A}$ and $\boldsymbol{C}$. $\boldsymbol{E}$, High-power view of a (plx3/4 DKO cone photoreceptor terminal triple labeled with antibodies against GluA2 (green), Calbindin (red), and peanut agglutinin (PNA, blue). The merge displays an overlay of a confocal (Calbindin, PNA) and a STED (GluA2) image. Arrowheads point to single GluA2-positive clusters at the cone photoreceptor terminal. Scale bar in $\boldsymbol{A}$ applies to $A$ and $\boldsymbol{C}, 10 \mu \mathrm{m}$; scale bar in $\boldsymbol{E}, 2 \mu \mathrm{m}$.

adapted rod photoreceptors from $204 \mathrm{~nm}$ (Cplx3/4 WT) to 244 $\mathrm{nm}(\mathrm{Cplx} 3 / 4 \mathrm{DKO})$, and of light-adapted rod photoreceptors from $225 \mathrm{~nm}$ (Cplx3/4 WT) to $241 \mathrm{~nm}$ (Cplx3/4 DKO).

The depletion of synaptic vesicles at the ribbon base upon light stimulation in Cplx3/4 WT mouse retina is the opposite of what was reported for lizard retina (Jackman et al., 2009). We have no explanation for this difference, but results for rat photoreceptor ribbons also show a significantly $(p<0.001, t$ test) reduced number of synaptic vesicles at the ribbon base in the light-adapted state (mean \pm SD; cones: $24.2 \pm 12.7 \%, n=97$; rods: $12.2 \pm 11.6 \%, n=238$ ) compared with the dark-adapted state (mean \pm SD; cones: $34.5 \pm 8.9 \%, n=120$; rods: $35.0 \pm$ $9.4 \%, n=202$ ), corroborating the results for Cplx3/4 WT mouse photoreceptor ribbons.

To study the adaptation-dependent number and distribution of synaptic vesicles on the ribbon in more detail, we repeated the experiments with WT BL/6 mice. We found previously that photoreceptor ribbons in $\mathrm{BL} / 6$ mice do not undergo illuminationdependent size and shape changes (Fuchs et al., 2013). BL/6 mice were dark or light adapted for $3 \mathrm{~h}$ and subsequently exposed to 1 , 10 , or 15 min of light or dark. First, and importantly, the results for $\mathrm{BL} / 6$ photoreceptors after $3 \mathrm{~h}$ of dark or light adaptation confirmed the results obtained with Cplx $3 / 4 \mathrm{WT}$ photoreceptors (Fig. 10), showing a clear reduction of synaptic vesicles at the ribbon base in the light-adapted state (Fig. 11). In dark-adapted $\mathrm{BL} / 6$ cone photoreceptors, $1 \mathrm{~min}$ of light exposure caused a slight decrease in synaptic vesicle number; after $15 \mathrm{~min}$, the synaptic vesicle number corresponded to the one seen with $3 \mathrm{~h}$ of light adaptation (Fig. $11 A, B$ ). In light-adapted BL/6 cone photoreceptors, 1 min of dark exposure led to a strong increase in synaptic vesicle number; after $15 \mathrm{~min}$, synaptic vesicle number was close to that after $3 \mathrm{~h}$ of dark exposure (Fig. $11 \mathrm{~A}, B$ ). The timing of the adaptation-dependent appearance of the synaptic vesicles at the ribbon base in $\mathrm{BL} / 6$ rod photoreceptors was comparable to the one seen in BL/6 cone photoreceptors (Fig. 11C,D).

In summary, the quantitative electron microscopic analysis of synaptic vesicles associated with the base of the ribbon in mice (Cplx3/4 WT, Cplx3/4 DKO, BL/6) and rat cone and rod photoreceptors after light and dark adaptation yielded two novel results: (1) the number of synaptic vesicles at the ribbon base did not change in Cplx3/4 DKO photoreceptors regardless of the adaptational state, which was strikingly different from the WT photoreceptors, and (2) the number of synaptic vesicles at the ribbon base in WT mice and rat photoreceptors was significantly lower in the light-adapted state than in the dark-adapted state.

\section{Discussion}

Loss-of-function studies have indicated inhibitory and facilitatory activities of Cplxs in SNARE-mediated vesicle fusion and distinct Cplx domains were suggested to be responsible for the opposing functions (Xue et al., 2007; Maximov et al., 2009; Kaeser-Woo et al., 2012; Yang et al., 2013; Lai et al., 2014; Chang et al., 2015; for review see Trimbuch and Rosenmund, 2016). Although most of our knowledge about Cplx function stems from studies on Cplx1 and Cplx2 present at conventional brain synapses, little is known about Cplx function at sensory synapses.

In the mouse auditory system, Cplxs were not detected in cochlear hair cells, but Cplx1 was found in spiral ganglion 

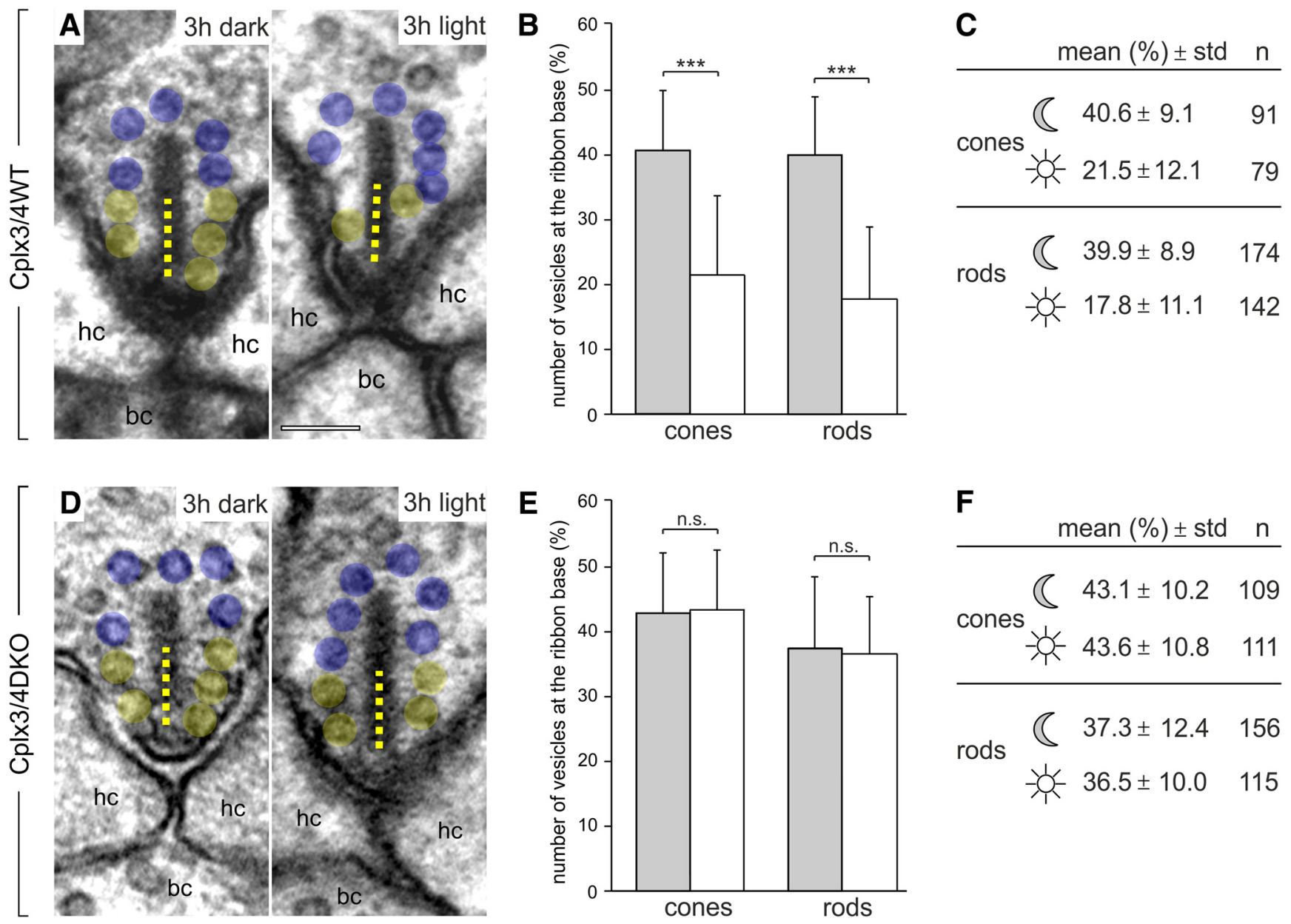

Figure 10. Quantification of synaptic vesicles associated with the ribbon base in Cplx3/4 WT and Cplx3/4 DKO cone and rod photoreceptors. $A, D$, Electron micrographs of cone photoreceptor ribbons from Cplx3/4 WT (A) and Cplx3/4 DKO (D) retinas fixed after $3 \mathrm{~h}$ of dark adaptation and $3 \mathrm{~h}$ of light adaptation. Ribbon-associated vesicles within the basal $100 \mathrm{~nm}$ (dotted line) of the ribbon are highlighted in yellow, the remaining ribbon-associated vesicles in blue. $\boldsymbol{B}, \boldsymbol{E}$, Percentage (mean \pm SD) of vesicles at the ribbon base in cone and rod photoreceptor ribbons from (plx $3 / 4$ WT ( $\boldsymbol{B}$ ) and (plx3/4 DKO (E) retinas fixed after $3 \mathrm{~h}$ of dark (gray bars) adaptation and $3 \mathrm{~h}$ of light (white bars) adaptation. ${ }^{* * *} p<0.001, t$ test. $\boldsymbol{C}, \boldsymbol{F}$, Summary of the quantitative data. $n=$ number of quantified ribbons; hc, horizontal cell; bc, bipolar cell. Scale bar in $\boldsymbol{A}$ applies to $\boldsymbol{A}$ and $\boldsymbol{D}, 100 \mathrm{~nm}$.

neurons and at the end bulb of Held in the cochlear nucleus (Strenzke et al., 2009; Chang et al., 2015). In the mouse retina, all four Cplx isoforms were detected with Cplx3 and Cplx4 present at photoreceptor ribbon synapses (Reim et al., 2005). Cplx3/4 DKO perturbed synaptic transmission at both photoreceptor and bipolar cell ribbon synapses, changed the temporal structure of synaptic processing in the inner plexiform layer, perturbed vision, and differentially affected the $\mathrm{ON}$ and OFF pathways in a light-dependent manner (Reim et al., 2009; Landgraf et al., 2012). So far, functional analyses of the Cplx3/4 DKO retina have been restricted to ERG recordings and multielectrode recordings of ganglion cell activity, that is, methods that assess the whole retinal circuitry or large neuronal populations but do not allow studying synaptic functions of Cplx3/4.

Here, we selectively studied the photoreceptor ribbon synaptic function of Cplx $3 / 4$. We recorded tonic activity in light and dark, light responses, and electrically evoked responses from postsynaptic HCs in a slice preparation of Cplx $3 / 4 \mathrm{WT}$ and Cplx3/4 DKO mouse retinas. Mouse retinal HCs receive input from cone and rod photoreceptors (Peichl et al., 1998), express AMPA and kainate types of glutamate receptors, and are depolarized in darkness (Hack et al., 2001; Feigenspan and Babai, 2015). Furthermore, we quantified ultrastructurally the number of synaptic vesicles associated with cone and rod photoreceptor ribbons in mouse (Cplx3/4 WT, Cplx3/4 DKO, BL/6) and rat retinas after different light and dark intervals.

\section{Suppressing action of $\mathrm{Cplx} 3 / 4$ on $\mathrm{Ca}^{2+}$-dependent tonic neurotransmitter release from photoreceptor ribbon synapses}

HCs from Cplx3/4 DKO retinas showed increased tonic activity and altered light responses. $\mathrm{Ca}^{2+}$ imaging and anatomical analyses indicate that these effects are not caused by altered cone photoreceptor intraterminal $\mathrm{Ca}^{2+}$ concentrations or by mislocalization of presynaptic $\mathrm{Ca}^{2+}$ channels or postsynaptic AMPAtype glutamate receptors.

The increased frequency of baseline EPSCs in HCs of Cplx $3 / 4$ DKO mice indicates higher rates of synaptic vesicle fusion in presynaptic photoreceptors. Because the number of synaptic vesicles at the ribbon base was comparable between Cplx $3 / 4 \mathrm{WT}$ and Cplx3/4 DKO mice in dark conditions, one function of Cplx 3 and Cplx4 appears to relate to the prevention of $\mathrm{Ca}^{2+}$-dependent tonic vesicle fusion. Furthermore, the amplitude distribution of baseline EPSCs was broadened in Cplx3/4 DKO mice, with a higher frequency of small-amplitude events evoked by release of one or two vesicles and large amplitude events, most likely reflecting multivesicular release. Comparison of normalized cur- 


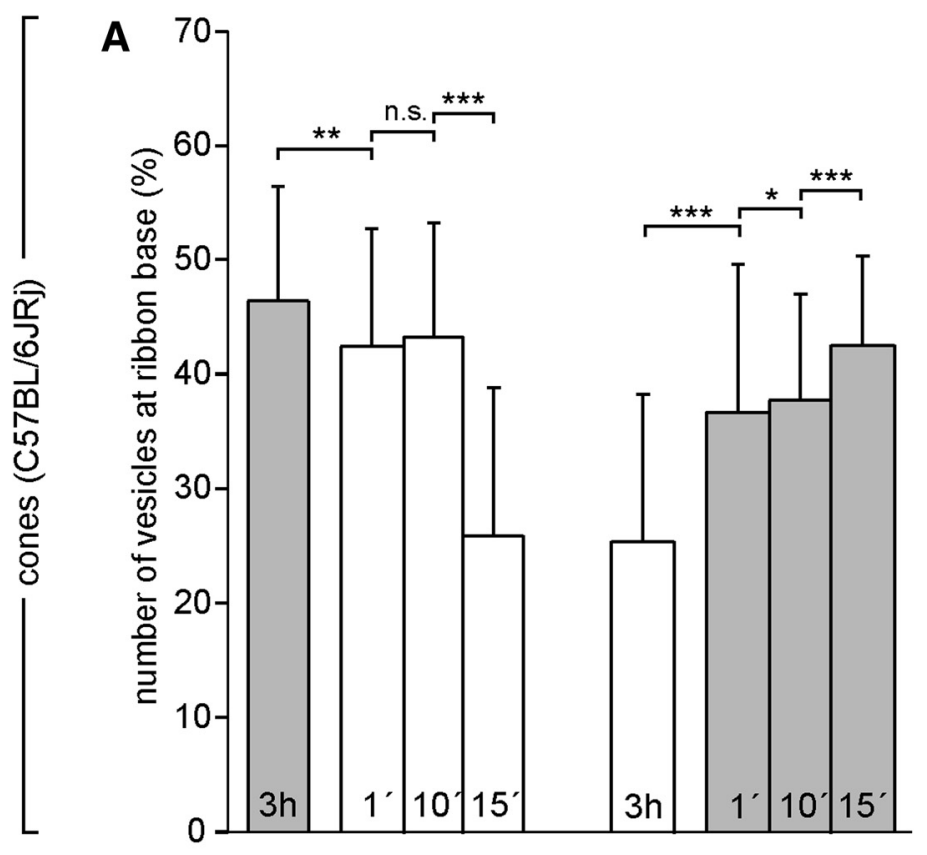

B

\begin{tabular}{|c|c|c|c|c|}
\hline & mear & (\%) & $\pm s$ & $\mathrm{n}$ \\
\hline $3 \mathrm{~h}$ & 46.3 & \pm & 9.7 & 102 \\
\hline $1^{\prime}$ & 42.4 & \pm 1 & 10.5 & 115 \\
\hline $10^{\prime}$ & 43.3 & \pm & 10.0 & 118 \\
\hline $15^{\circ}$ & 25.7 & \pm & 13.0 & 116 \\
\hline $3 h$ & 25.5 & \pm & 13.1 & 118 \\
\hline $1^{\prime}$ & 36.6 & \pm & 12.8 & 110 \\
\hline $10^{\prime}$ & 37.6 & \pm & 9.3 & 135 \\
\hline $15^{\circ}$ & 42.5 & \pm & 7.7 & 135 \\
\hline
\end{tabular}

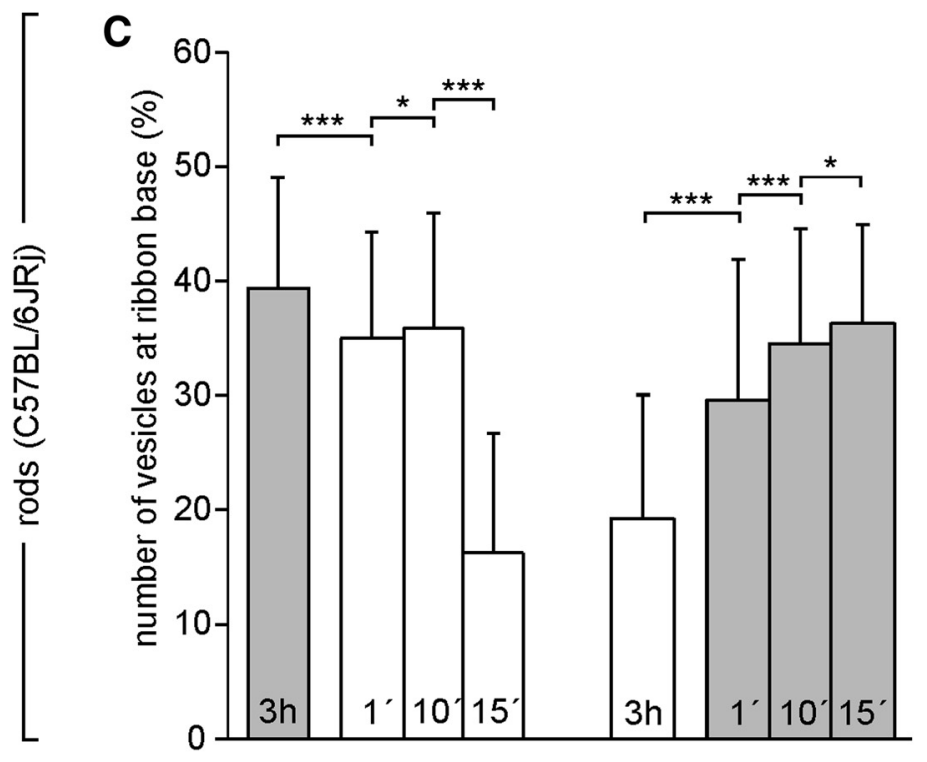

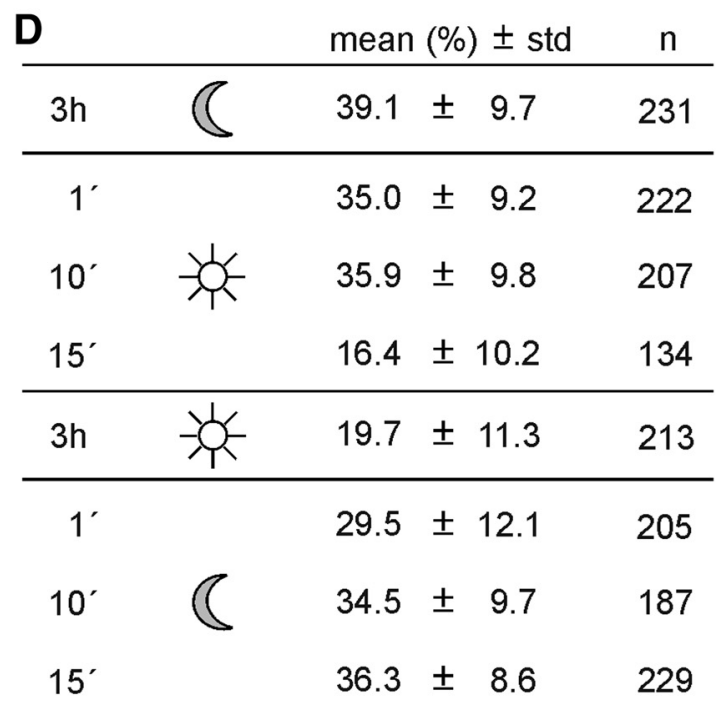

Figure 11. Quantification of synaptic vesicles associated with the ribbon base in (57BL/6JRj cone and rod photoreceptors after varying durations of light or dark. $A, C$, Percentage (mean \pm SD) of vesicles at the ribbon base in cone photoreceptor ribbons $(\boldsymbol{A})$ and rod photoreceptor ribbons $(\boldsymbol{C})$ from $(57 \mathrm{BL} / 6 \mathrm{~J} \mathrm{Rj}$ retinas fixed after different periods of light adaptation $(1,10,15 \mathrm{~min}$, white bars) and after different periods of dark adaptation $\left(1,10,15\right.$ min, gray bars). ${ }^{*} p<0.05,{ }^{* *} p<0.01,{ }^{* * *} p<0.001, t$ test. $\boldsymbol{B}, \boldsymbol{D}$, Summary of the quantitative data. $n=$ number of quantified ribbons.

rent trajectories revealed prolonged kinetics of synaptic events in Cplx3/4 DKO mice. Because individual quanta sum linearly to generate larger-amplitude events (Cadetti et al., 2005, 2006), the observed changes in rise and decay times of baseline EPSCs in Cplx3/4 DKO mice could be a direct consequence of impaired synchronization of release, confounding precise coordination of synaptic vesicle fusion at the cone photoreceptor ribbon synapse.

Most strikingly, light responses of HCs from Cplx3/4 DKO mice were more sensitive, displayed larger amplitudes, and showed an increased current during prolonged illumination and the levels of tonic synaptic activity in the light were indistinguishable from those in the dark. Higher sensitivity and larger amplitudes of HC light responses could be attributed to an increased baseline activity caused by an $\sim 2$-fold higher rate of glutamate release from Cplx3/4 DKO photoreceptors in dark. The transient nature of the HC light responses during prolonged illumination is most likely due to asynchronous release from photoreceptors resuming shortly after light onset. Together, our data demonstrate that in both dark and light Cplx3/4 DKO cone photoreceptors show a higher release rate compared with Cplx3/4 WT. We conclude that Cplx3 and Cplx4 suppress $\mathrm{Ca}^{2+}$-dependent tonic synaptic vesicle fusion at WT photoreceptor ribbon synapses.

A suppressing function of Cplxs in spontaneous release was shown in zebrafish photoreceptors, mouse rod bipolar cells (Vaithianathan et al., 2013, 2015), and neuromuscular junctions from worm and fly (Huntwork and Littleton, 2007; Hobson et al., 2011; Martin et al., 2011). Inhibiting Cplx3 function increased spontaneous release and significantly reduced the reserve pool of vesicles in mouse rod bipolar cells (Vaithianathan et al., 2015). 
In a previous study, analyzing Cplx3/4 DKOs with ERG recordings, we interpreted the decreased ERG b-wave to indicate reduced synaptic release from photoreceptors, ascribing $\mathrm{Cplx} 3 / 4$ a facilitating function in transmitter release (Reim et al., 2009). The b-wave reflects voltage changes in ON bipolar cells, which are depolarized at light onset due to a sign-inverting synapse signaling decreases in synaptic glutamate. Therefore, a reduction in b-wave amplitude in Cplx3/4 DKO mice can be explained by a continuous increased release in light, exactly what we report in the present study.

\section{Facilitating action of Cplx3/4 on evoked neurotransmitter release from photoreceptor ribbon synapses}

To explore Cplx $3 / 4$ function during evoked release at photoreceptor ribbon synapses, we electrically stimulated photoreceptors while recording currents from postsynaptic HCs. We did not use pharmacological tools to explore whether postsynaptic receptor desensitization or saturation influences replenishment rates. If glutamate release during electrical stimulation caused a progressive increase in receptor saturation or desensitization, one would expect to see an advanced decrease in the replenishment rate. Because we never observed such an effect, desensitization and saturation of postsynaptic receptors apparently did not play a role in our measurements.

The decreased peak amplitude and charge transfer values of evoked postsynaptic currents in Cplx3/4 DKO mice indicate decreased synaptic vesicle release rates and thus a facilitatory role of Cplx3/4 in an evoked release paradigm. Here, the intraterminal $\mathrm{Ca}^{2+}$ concentration is likely to be higher due to a strong and synchronized activation of voltage-gated $\mathrm{Ca}^{2+}$ channels than during tonic release in the dark, where Cplx3/4 exerts a suppressing function on baseline EPSCs.

Knock-down of Cplx3 in rod bipolar cells decreased evoked release at the cells' ribbon synapses while enhancing spontaneous vesicle fusion (Vaithianathan et al., 2015). The pool size of ribbonassociated vesicles was not affected in this study, suggesting impaired exocytosis of vesicles when Cplx 3 was rendered nonfunctional. Our results indicate that deficiency of $\mathrm{Cp} 1 \mathrm{x} 3 / 4$ might cause a reduction of the releasable vesicle pool size (Fig. 8). However, pool size estimates are likely to represent only a fraction of the pool size because of limited stimulation strength (Thoreson et al., 2016) and the behavior of Cplx $3 / 4$ in photoreceptors might differ from rod bipolar cells, which only have Cplx3.

The smaller slope in the charge transfer measurements in the absence of Cplx3/4 (Fig. 7) indicates decreased $\mathrm{Ca}^{2+}$ cooperativity after disturbed interaction with proteins of the SNARE complex and/or the $\mathrm{Ca}^{2+}$ sensor. Whereas vesicle replenishment rates appeared not to be affected in the Cplx3/4 DKO, the variance of evoked EPSC amplitudes was significantly reduced (Table 1), suggesting a role for $\mathrm{Cplx} 3 / 4$ in determining release probability at photoreceptor synapses. Furthermore, evoked EPSCs revealed similar replenishment rates in Cplx3/4 WT and Cplx3/4 DKO mice, but a $\sim 3$-fold smaller releasable pool size in the absence of both Cplxs. The reduced variance of evoked EPSC amplitudes in the $\mathrm{Cplx} 3 / 4 \mathrm{DKO}$ at higher stimulation frequencies suggests a smaller release probability in Cplx3/4 DKO mice.

The most straightforward interpretation of $\mathrm{Cplx} 3 / 4$ function in photoreceptor ribbon synaptic release is the suppression of $\mathrm{Ca}^{2+}$-dependent tonic release and the facilitation of evoked synchronous and asynchronous release. However, HCs receive synaptic input from both cone and rod photoreceptors, creating a level of complexity that makes a clear assignment of the contribution of both photoreceptor types to the respective release components difficult and a challenging task for future studies.

\section{Regulatory role of $\mathrm{Cplx} 3 / 4$ in the adaptation-dependent availability of synaptic vesicles for release from photoreceptor ribbon synapses}

Photoreceptor ribbon synaptic output continuously adapts to changes in light intensity. Dynamic changes in ribbon structure have been suggested to regulate the number of releasable synaptic vesicles and adapt the ribbon synapse to different light regimes (Spiwoks-Becker et al., 2004). Recently, however, we showed that illumination-dependent structural remodeling of photoreceptor synaptic ribbons cannot be considered a general mechanism for light adaptation (Fuchs et al., 2013). A compelling hypothesis for the role of the synaptic ribbon in encoding steady and changing light was introduced by Jackman et al. (2009). Examining cone photoreceptor ribbon synaptic function in salamander and lizard retinas, they observed that the ribbon base was depleted of synaptic vesicles in darkness and reloaded with vesicles in light. Therefore, they suggested that the synaptic ribbon operates like a leaky capacitor, charging with vesicles in light and discharging in a phasic burst at light offset.

The most striking finding of our quantitative electron microscopic study was that both cone and rod photoreceptors from Cplx3/4 DKO mice lacked an adaptation-dependent change of synaptic vesicle distribution at the ribbon base. Regardless of light or dark adaptation, Cplx3/4 DKO ribbons were always loaded with synaptic vesicles and the ribbon base was never depleted of synaptic vesicles. This is in contrast to Cplx $3 / 4 \mathrm{WT}, \mathrm{BL} / 6$, and rat cone and rod photoreceptors, which showed an adaptation dependency in the distribution of synaptic vesicles on the synaptic ribbon. Light-adapted WT photoreceptor ribbons had a significant deficit of synaptic vesicles, particularly within $100 \mathrm{~nm}$ of the ribbon base directly adjacent to the release site. One minute of dark exposure led to a strong increase in synaptic vesicle number at the ribbon base. Such an adaptation-dependent regulation in the availability of synaptic vesicles for release may play a role in minimizing noise and maximizing the dynamic range of the tonically active ribbon synapse.

\section{References}

Babai N, Bartoletti TM, Thoreson WB (2010) Calcium regulates vesicle replenishment at the cone ribbon synapse. J Neurosci 30:15866-15877. CrossRef Medline

Brose N (2008) For better or for worse: complexins regulate SNARE function and vesicle fusion. Traffic 9:1403-1413. CrossRef Medline

Cadetti L, Tranchina D, Thoreson WB (2005) A comparison of release kinetics and glutamate receptor properties in shaping rod-cone differences in EPSC kinetics in the salamander retina. J Physiol 569:773-788. CrossRef Medline

Cadetti L, Bryson EJ, Ciccone CA, Rabl K, Thoreson WB (2006) Calciuminduced calcium release in rod photoreceptor terminals boosts synaptic transmission during maintained depolarization. Eur J Neurosci 23:29832990. Medline

Chang S, Reim K, Pedersen M, Neher E, Brose N, Taschenberger H (2015) Complexin stabilizes newly primed synaptic vesicles and prevents premature fusion at the mouse Calyx of Held synapse. J Neurosci 35:8272-8290. CrossRef Medline

Cooper B, Hemmerlein M, Ammermüller J, Imig C, Reim K, Lipstein N, Kalla S, Kawabe H, Brose N, Brandstätter JH, Varoqueaux F (2012) Munc13independent vesicle priming at mouse photoreceptor ribbon synapses. J Neurosci 32:8040-8052. CrossRef Medline

Dick O, Hack I, Altrock WD, Garner CC, Gundelfinger ED, Brandstätter JH (2001) Localization of the presynaptic cytomatrix protein Piccolo at ribbon and conventional synapses in the rat retina: comparison with Bassoon. J Comp Neurol 439:224-234. CrossRef Medline

Feigenspan A, Babai N (2015) Functional properties of spontaneous excitatory currents and encoding of light/dark transitions in horizontal cells of the mouse retina. Eur J Neurosci 42:2615-2632. CrossRef Medline

Fuchs M, Sendelbeck A, Atorf J, Kremers J, Brandstätter JH (2013) Strain 
differences in illumination-dependent structural changes at mouse photoreceptor ribbon synapses. J Comp Neurol 521:69-78. CrossRef Medline

Fuchs M, Brandstätter JH, Regus-Leidig H (2014) Evidence for a Clathrinindependent mode of endocytosis at a continuously active sensory synapse. Front Cell Neurosci 8:60. CrossRef Medline

Gee KR, Brown KA, Chen WN, Bishop-Stewart J, Gray D, Johnson I (2000) Chemical and physiological characterization of fluo- $4 \mathrm{Ca}(2+)$-indicator dyes. Cell Calcium 27:97-106. CrossRef Medline

Gundelfinger ED, Fejtova A (2012) Molecular organization and plasticity of the cytomatrix at the active zone. Curr Opin Neurobiol 22:423-430. CrossRef Medline

Hack I, Peichl L, Brandstätter JH (1999) An alternative pathway for rod signals in the rodent retina: rod photoreceptors, cone bipolar cells, and the localization of glutamate receptors. Proc Natl Acad Sci U S A 96: 14130-14135. CrossRef Medline

Hack I, Frech M, Dick O, Peichl L, Brandstätter JH (2001) Heterogeneous distribution of AMPA glutamate receptor subunits at the photoreceptor synapses of rodent retina. Eur J Neurosci 13:15-24. CrossRef Medline

Hasegawa J, Obara T, Tanaka K, Tachibana M (2006) High-density presynaptic transporters are required for glutamate removal from the first visual synapse. Neuron 50:63-74. CrossRef Medline

Heidelberger R (2007) Mechanisms of tonic, graded release: lessons from the vertebrate photoreceptor. J Physiol 585:663-667. CrossRef Medline

Higgs MH, Lukasiewicz PD (1999) Glutamate uptake limits synaptic excitation of retinal ganglion cells. J Neurosci 19:3691-3700. Medline

Hobson RJ, Liu Q, Watanabe S, Jorgensen EM (2011) Complexin maintains vesicles in the primed state in C. elegans. Curr Biol 21:106-113. CrossRef Medline

Huntwork S, Littleton JT (2007) A complexin fusion clamp regulates spontaneous neurotransmitter release and synaptic growth. Nat Neurosci 10: 1235-1237. CrossRef Medline

Jackman SL, Choi SY, Thoreson WB, Rabl K, Bartoletti TM, Kramer RH (2009) Role of the synaptic ribbon in transmitting the cone light response. Nat Neurosci 12:303-310. CrossRef Medline

Kaeser-Woo YJ, Yang X, Südhof TC (2012) C-terminal complexin sequence is selectively required for clamping and priming but not for $\mathrm{Ca}^{2+}$ triggering of synaptic exocytosis. J Neurosci 32:2877-2885. CrossRef Medline

Lai Y, Diao J, Cipriano DJ, Zhang Y, Pfuetzner RA, Padolina MS, Brunger AT (2014) Complexin inhibits spontaneous release and synchronizes Ca2+triggered synaptic vesicle fusion by distinct mechanisms. Elife 13;3: e03756. CrossRef Medline

Landgraf I, Mühlhans J, Dedek K, Reim K, Brandstätter JH, Ammermüller J (2012) The absence of complexin 3 and complexin 4 differentially impacts the ON and OFF pathways in mouse retina. Eur J Neurosci 36:24702481. CrossRef Medline

Martin JA, Hu Z, Fenz KM, Fernandez J, Dittman JS (2011) Complexin has opposite effects on two modes of synaptic vesicle fusion. Curr Biol 21: 97-105. CrossRef Medline

Matthews G, Fuchs P (2010) The diverse roles of ribbon synapses in sensory neurotransmission. Nat Rev Neurosci 11:812-822. CrossRef Medline

Maxeiner S, Luo F, Tan A, Schmitz F, Südhof TC (2016) How to make a synaptic ribbon: RIBEYE deletion abolishes ribbons in retinal synapses and disrupts neurotransmitter release. EMBO J. 35:1098-1114.

Maximov A, Tang J, Yang X, Pang ZP, Südhof TC (2009) Complexin controls the force transfer from SNARE complexes to membranes in fusion. Science 323:516-521. CrossRef Medline

Moore-Dotson JM, Klein JS, Mazade RE, Eggers ED (2015) Different types of retinal inhibition have distinct neurotransmitter release properties. J Neurophysiol 113:2078-2090. CrossRef Medline

Peichl L, Sandmann D, Boycott BB (1998) Comparative anatomy and function of mammalian horizontal cells. In: Development and organization of the retina (Chalupa LM, Finlay BL. eds), pp 147-172. New York: Plenum.

Regus-Leidig H, Brandstätter JH (2012) Structure and function of a complex sensory synapse. Acta Physiol (Oxf) 204:479-486. CrossRef Medline

Regus-Leidig H, Ott C, Löhner M, Atorf J, Fuchs M, Sedmak T, Kremers J, Fejtová A, Gundelfinger ED, Brandstätter JH (2013) Identification and immunocytochemical characterization of Piccolino, a novel Piccolo splice variant selectively expressed at sensory ribbon synapses of the eye and ear. PLoS One 8:e70373. CrossRef Medline

Regus-Leidig H, Fuchs M, Löhner M, Leist SR, Leal-Ortiz S, Chiodo VA, Hauswirth WW, Garner CC, Brandstätter JH (2014a) In vivo knock- down of Piccolino disrupts presynaptic ribbon morphology in mouse photoreceptor synapses. Front Cell Neurosci 8:259. CrossRef Medline

Regus-Leidig H, Atorf J, Feigenspan A, Kremers J, Maw MA, Brandstätter JH (2014b) Photoreceptor degeneration in two mouse models for congenital stationary night blindness type 2. PLoS One 9:e86769. CrossRef Medline

Reim K, Mansour M, Varoqueaux F, McMahon HT, Südhof TC, Brose N, Rosenmund C (2001) Complexins regulate a late step in $\mathrm{Ca}^{2+}$ dependent neurotransmitter release. Cell 104:71-81. CrossRef Medline

Reim K, Wegmeyer H, Brandstätter JH, Xue M, Rosenmund C, Dresbach T, Hofmann K, Brose N (2005) Structurally and functionally unique complexins at retinal ribbon synapses. J Cell Biol 169:669-680. CrossRef Medline

Reim K, Regus-Leidig H, Ammermüller J, El-Kordi A, Radyushkin K, Ehrenreich $\mathrm{H}$, Brandstätter JH, Brose N (2009) Aberrant function and structure of retinal ribbon synapses in the absence of complexin 3 and complexin 4. J Cell Sci 122:1352-1361. CrossRef Medline

Schmitz F, Königstorfer A, Südhof TC (2000) RIBEYE, a component of synaptic ribbons: a protein's journey through evolution provides insight into synaptic ribbon function. Neuron 28:857-872. CrossRef Medline

Schneggenburger R, Meyer AC, Neher E (1999) Released fraction and total size of a pool of immediately available transmitter quanta at a calyx synapse. Neuron 23:399-409. CrossRef Medline

Specht D, Wu SB, Turner P, Dearden P, Koentgen F, Wolfrum U, Maw M, Brandstätter JH, tom Dieck S (2009) Effects of presynaptic mutations on a postsynaptic Cacna1s calcium channel colocalized with mGluR6 at mouse photoreceptor ribbon synapses. Invest Ophthalmol Vis Sci 50: 505-515. CrossRef Medline

Spiwoks-Becker I, Glas M, Lasarzik I, Vollrath L (2004) Mouse photoreceptor synaptic ribbons lose and regain material in response to illumination changes. Eur J Neurosci 19:1559-15571. CrossRef Medline

Sterling P, Matthews G (2005) Structure and function of ribbon synapses. Trends Neurosci 28:20-29. CrossRef Medline

Strenzke N, Chanda S, Kopp-Scheinpflug C, Khimich D, Reim K, Bulankina AV, Neef A, Wolf F, Brose N, Xu-Friedman MA, Moser T (2009) Complexin-I is required for high-fidelity transmission at the endbulb of Held auditory synapse. J Neurosci 29:7991-8004. CrossRef Medline

Thoreson WB, Rabl K, Townes-Anderson E, Heidelberger R (2004) A highly $\mathrm{Ca}^{2+}$-sensitive pool of vesicles contributes to linearity at the rod photoreceptor ribbon synapse. Neuron 42:595-605. CrossRef Medline

Thoreson WB, Van Hook MJ, Parmelee C, Curto C (2016) Modeling and measurement of vesicle pools at the cone ribbon synapse: Changes in release probability are solely responsible for voltage-dependent changes in release. Synapse 70:1-14. CrossRef Medline

tom Dieck S, Brandstätter JH (2006) Ribbon synapses of the retina. Cell Tissue Res 326:339-346. CrossRef Medline

tom Dieck S, Altrock WD, Kessels MM, Qualmann B, Regus H, Brauner D, Fejtová A, Bracko O, Gundelfinger ED, Brandstätter JH (2005) Molecular dissection of the photoreceptor ribbon synapse: physical interaction of Bassoon and RIBEYE is essential for the assembly of the ribbon complex. J Cell Biol 168:825-836. CrossRef Medline

Trimbuch T, Rosenmund C (2016) Should I stop or should I go? The role of complexin in neurotransmitter release. Nat Rev Neurosci 17:118-125. CrossRef Medline

Vaithianathan T, Zanazzi G, Henry D, Akmentin W, Matthews G (2013) Stabilization of spontaneous neurotransmitter release at ribbon synapses by ribbon-specific subtypes of complexin. J Neurosci 33:8216-8226. CrossRef Medline

Vaithianathan T, Henry D, Akmentin W, Matthews G (2015) Functional roles of complexin in neurotransmitter release at ribbon synapses of mouse retinal bipolar neurons. J Neurosci 35:4065-4070. CrossRef Medline

Xue M, Reim K, Chen X, Chao HT, Deng H, Rizo J, Brose N, Rosenmund C (2007) Distinct domains of complexin I differentially regulate neurotransmitter release. Nat Struct Mol Biol 14:949-958. CrossRef Medline

Yamada KA, Tang CM (1993) Benzothiazides inhibit rapid glutamate receptor desensitization and enhance glutamatergic synaptic currents. J Neurosci 13:3904-3915. Medline

Yang X, Cao P, Südhof TC (2013) Deconstructing complexin function in activating and clamping $\mathrm{Ca}^{2+}$-triggered exocytosis by comparing knockout and knockdown phenotypes. Proc Natl Acad Sci U S A 110:2077720782. CrossRef Medline

Zhai RG, Bellen HJ (2004) The architecture of the active zone in the presynaptic nerve terminal. Physiology (Bethesda) 19:262-270. CrossRef Medline 